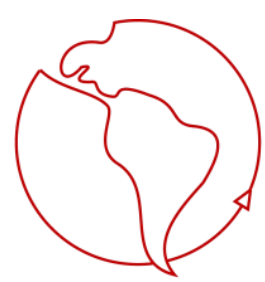

\title{
La confianza institucional y el proyecto bolivariano en el contexto Venezolano
}

\author{
Cesar Mariñez
}

Magíster en Análisis Sistémico aplicado a la Sociedad, Universidad de Chile cdmarinez@gmail.com

Resumen

El presente trabajo aborda el estudio de la confianza institucional en la sociedad venezolana. Busca determinar si el reforzamiento ideológico ("Nuevo Socialismo Bolivariano del Siglo XXI") posibilita o dificulta la construcción de confianza institucional en dicho país. Desde la perspectiva de la teoría de los Sistemas Sociales se analizará este proceso político y se establecerán sus relaciones con el problema de la confianza, desde una mirada de la complejidad.

\section{Abstract}

This paper addresses the study of institutional trust in Venezuelan society. It seeks to determine whether the ideological reinforcement ("New Century Bolivarian Socialism XXI") enables or hinders the construction of institutional trust in that country. From the perspective of the theory of social systems will analyze the political process and establish their relations with the issue of trust, from a viewpoint of complexity.

Palabras Clave: Confianza, teoría de los sistemas sociales, ideología, instituciones, políticas

Keywords: Trust, social systems theory, ideology, institutions, policies

\section{Introducción}

Las investigaciones que se han realizado sobre los proyectos de modernización en los países latinoamericanos en la década de los 90 han demostrado que una gran parte de los sectores más vulnerables fueron afectados por las decisiones tomadas por los Estados Nacionales. Se dice que ni las políticas neoliberales ni el orden institucional tradicional fueron capaces de ofrecer resultados positivos para mantener las expectativas públicas en este Continente. Los principales temas tratados por los cientistas sociales en esta década hacen referencia a la corrupción, la pobreza, el desempleo y para muchos países, el acceso a servicios públicos tal como la salud, la educación o la vivienda para concluir que éstos serían los factores que incidieron en el debilitamiento de las instituciones del Estado.

Por ejemplo, según los datos de la CEPAL, la tasa de desempleo en América Latina de 1980 al 2000 habría aumentado. Argentina para 1980, la tasa de desempleo se encontraba en un $2.6 \%$ y 20 años más tarde, en 2000 aumenta a un $15.1 \%$, tomando en cuenta que para 1996 la tasa se encontraba en un 17.2\%. Colombia también resulta ser un país afectado por el desempleo. En 1980 lo encontramos con una tasa del 10\% mientras que para el año 2000 aumenta a 17.3\%. El aumento también se observa en Uruguay, quien estaba para en 1980 en un $7.4 \%$, y para el 2000 se 
encontraba en $13.6 \%$. En el contexto venezolano a principios de los 80 este país tenía un $6.0 \%$ y para el año 2000 la tasa de desempleo aumenta a 13.9\%. Otro ejemplo lo podemos encontrar en la tasa de pobreza a principio de los 90 , quien se encontraba casi en un $50 \%$ y pudo reducirse en América Latina únicamente en un $4.4 \%$ en casi 10 años. Según los datos proporcionados por la CEPAL, en el año 1999 la pobreza en Bolivia y en Paraguay se encontraría en un $60,6 \%$. En Colombia con un $54.9 \%$, Perú con un $48.6 \%$, Venezuela con un $49.4 \%$. Con menos del $40 \%$ nos encontramos a Brasil con un $37.5 \%$.

En el caso concreto de nuestro objeto de estudio, en Venezuela, con la llegada del Movimiento Bolivariano al poder en el año 1999 se abren nuevas perspectivas de futuro para el país. El nuevo modelo Gobierno/Estado propone una solución al debilitamiento del orden institucional tradicional y se abren nuevas expectativas para la población venezolana. Se buscaba recuperar y fortalecer a las instituciones tradicionales para darles una característica universal y equitativa para garantizarles a los ciudadanos sus derechos sociales y económicos. De igual manera, el nuevo Estado Social de Derecho buscaba avanzar hacia poderes públicos abiertos para que los ciudadanos tuviesen la posibilidad de organizarse y de participar en la gestión pública. Sin embargo, varios acontecimientos ocurren en el proceso sociopolítico que se vive en este país y el gobierno bolivariano irá poco a poco adoptando una visión política que lo irá direccionando hacia el Nuevo Socialismo Bolivariano del Siglo XXI. El objetivo será de liberar a la sociedad venezolana de la influencia de los sectores económicos capitalistas (Cabezas 2008). Como veremos más adelante, esta visión actuaría fuera del orden institucional e iría desplazando de los espacios estratégicos a los poderes de la democracia tradicional (Elia 2009).

El presente texto intenta analizar el problema de la confianza hacia las instituciones en el contexto venezolano desde la llegada del Movimiento Bolivariano al poder. Intentamos aproximarnos a la pregunta de si el reforzamiento ideológico (El Nuevo Socialismo Bolivariano del Siglo XXI), posibilita o dificulta la construcción de la confianza institucional.

Para poder acercarnos a este problema, hemos dividido nuestra investigación en cuatro partes. La primera busca darle una mirada a la perspectiva teórica que utilizamos para estudiar el problema de la confianza institucional en el contexto venezolano. La segunda parte se llama: el proceso para la consolidación del proyecto bolivariano en el plano ideológico y político-institucional. Se busca en principio identificar los rasgos ideológicos del Movimiento Bolivariano para luego caracterizar en el plano políticoinstitucional, el modelo Estado/Gobierno que elabora el gobierno desde la nueva Constitución de 1999. Este material empírico nos ayudará a identificar los distintos temas que se retoman del sistema político tradicional venezolano para proponer un nuevo proyecto político alternativo a las políticas neoliberales y al debilitamiento del orden institucional tradicional. De estas propuestas, se observarán las visiones que se instalan en el gobierno y que lo irán direccionando hacia un nuevo modelo Gobierno/Estado, el cual es nuestro tercer apartado; el Nuevo Socialismo Bolivariano del Siglo XXI. En este, describiremos y analizaremos el nuevo modelo Estado/Gobierno que se intenta instalar en el contexto venezolano desde que se adopta una visión cívico-militar. Este material nos ayudará a visualizar el modelo ideológico que propone el gobierno bolivariano y la nueva institucionalidad que busca instalar. Por último, analizaremos precisamente a la confianza institucional en el Nuevo Socialismo Bolivariano del siglo XXI. Este capítulo nos ayudará a observar la posibilidad - la dificultad que tiene este reforzamiento ideológico para construir confianza institucional en el contexto venezolano. 


\section{La confianza}

El concepto de la confianza es visto según Niklas Luhmann (1996, 2000) como un mecanismo de reducción de complejidad, un concepto funcional (equivalente funcional) ya que soluciona problemas en las decisiones riesgosas que enfrentamos en nuestras relaciones sociales.

La confianza se relaciona con el tiempo ya que el tiempo en la sociedad moderna supondría "una ruptura de los horizontes de expectativas, una continua problematización de la acción futura [...] todo lo simultáneamente al instante es el motor que nos mueve" (Beriain 2008; 56). En los instantes, vivenciamos los acontecimientos, por lo que nos vemos forzados a tomar decisiones riesgosas para resolver nuestros problemas o reducir la complejidad en las relaciones sociales, en el presente. El problema de la confianza "consiste en el hecho de que el futuro contiene muchas más posibilidades de las que podrían actualizarse en el presente" (Luhmann 1996; 22), por lo que el tiempo es un mecanismo de reducción de complejidad, ya que el presente es considerado como el punto de partida que avanza continuamente hacia el futuro (Luhmann 1996). El futuro contiene más posibilidades que el presente y la seguridad es sólo posible en el presente, por lo que la confianza es una forma de seguridad. La seguridad "es la base de toda confianza como un continuo intacto de sucesos cambiantes como la totalidad de los estados con respecto al cual los sucesos pueden acontecer" (Luhmann 1996; 20).

La confianza tiene que ver con expectativa; una decisión que se toma en el aquí y ahora, con la ilusión que en el futuro se cumpla y con el riesgo de sufrir una decepción en el presente. De igual manera, las posibilidades de selección implican también un presente en el futuro, es decir, la selección de nuevos presentes y con ello nuevas perspectivas futuras (Luhmann 1996). Esto significa que cuando los presentes se actualizan, el futuro visible desde el presente tenga la posibilidad de durar para futuras acciones, nos ofrece la posibilidad de abrir nuevas perspectivas de futuro, posibilitando que el futuro "ya visible en un presente todavía dure" (Luhmann 1998; 93). Es lo es lo que posibilita las estructuras de expectativas, es decir, un ordenamiento de acciones (Luhmann 1998) que quedan limitadas para realizar la acción en los nuevos presentes. Más adelante veremos cómo estas estructuras de expectativas pueden emerger y pueden institucionalizarse.

En segundo lugar, la confianza también se relaciona con el sentido-mundo y la familiaridad. En el mundo, la experiencia resulta ser un prerrequisito fundamental para poder enfrentar la complejidad en que vivimos, "la experiencia es llevada al sentido organizado y al mundo con el objeto de hacer comprensibles las condiciones complejas de la existencia" (Luhmann 1996; 29). Tal como lo señala Niklas Luhmann (1996), el mundo se constituye como un horizonte universal de la experiencia que debe presuponerse en cada movimiento. El sentido-mundo "se presupone y coexperimenta a cualquier persona de la misma manera formal, vacía, de otro ego, como otro yo, impersonal [...] Cualquiera que no concuerde, no agitará la imagen del mundo comúnmente sostenida" (Heidegger en Luhmann 1996; 30). Desde la perspectiva Luhmaniana, al sentido-mundo se le agrega el componente de la contingencia y por lo tanto;

"El concepto de mundo no indica mas el fundamento, sino la contingencia de todo ser; después del giro nominalista del pensamiento ya no refiere más a una esfera cósmica de lo necesario, bajo la cual la facticidad del cambio, del 
movimiento, de lo puramente posible se transforma en un problema; sino que significa por el contrario la contingencia misma dentro de la cual ha llegado a ser un problema fundamentar necesidades, verdades, bellezas y validaciones" (Luhmann 1971: 379 en Mascareño 2009).

En este sentido, para Niklas Luhmann (1998), el mundo es mucho más que la suma del entendimiento de todas las posibilidades que nos ofrece el sentido, sino que también es la unidad de esas posibilidades:

"Lo que quiere decir sobre todo que el horizonte de mundo de cada diferencia garantiza su propia unidad como diferencia [...] Como sentido, el mundo es experimentable en todas partes: en cada situación, en cualquier detalle en particular, en cualquier punto de escala entre lo concreto y lo abstracto. Uno puede moverse desde cualquier punto hacia las otras posibilidades del mundo, lo cual quiere decir sobre todo que el horizonte de mundo está indicado en todo sentido" (Luhmann 1998; 86).

El sentido por lo tanto es el médium que permite la creación selectiva de todas las formas sociales y psíquicas y mantiene abierto el mundo en su conjunto y garantiza la actualidad del mundo bajo la forma de accesibilidad (Luhmann 1998). La accesibilidad es contingente y por lo tanto, la creación selectiva de formas sociales y psíquicas (sentido-mundo) -que siempre pueden ser diferentes- se relaciona con la familiaridad ya que esta última sería un inevitable hecho de la vida. La familiaridad es el mundo que experimentamos y que conocemos, mientras que la confianza sería una solución a un problema específico de riesgo (Luhmann 2000).

La familiaridad a diferencia de la confianza que se orienta a un futuro, tiene que ver con una función simbólica que se orienta al pasado. En la familiaridad, "el pasado prevalece sobre el presente y el futuro [...] los elementos esenciales de la experiencia deben representarse en la historia ya que la historia es la forma más importante de reducir complejidad" (Luhmann 1996; 33). En este sentido, lo familiar tiene que ver con lo vivenciado, el cual se deposita en la historia como algo que prevalece en el futuro. Esta es una precondición para la confianza o la desconfianza ya que son nuestras experiencias (lo familiar) las que nos permiten operar en el mundo que conocemos (Luhmann 1996). Lo familiar sería entonces un equivalente funcional a la confianza, una alternativa funcional que también reduce complejidad, con la única excepción que hace referencia al pasado, a lo vivido y que nos orienta a tomar decisiones para el futuro.

Según Niklas Luhmann (2000), en la sociedad moderna, el riesgo viene a formar parte de lo familiar ya que sabemos que en un futuro lleno de posibilidades corremos la posibilidad de sufrir decepciones. "Hace posible abrigar expectativas relativamente confiables y como consecuencia, hace posible contener los elementos restantes del riesgo (Luhmann 1996). Así, "la historia deja de ser un recuerdo de las cosas experimentadas y se vuelve simplemente una estructura predeterminada que es la base para la confianza en los sistemas sociales" (Luhmann 2000), es decir, una estructura (presente en el futuro), una cadena de acontecimientos que ordenan las acciones (Luhmann 1998) para abrirnos nuevas perspectiva de futuro.

En tercer lugar, además de la relación que mantiene el concepto de la confianza con el tiempo y con el mundo, también lo tiene con lo social. La dimensión social es "todo aquello que se supone lo respectivamente igual, como un alter-ego, y articula la relevancia de esta suposición para cada experiencia del mundo y fijación del sentido 
[...] tiene relevancia universal del mundo ya que si existe un alter ego, este es igual que ego, relevante para todos los objetos y los temas" (Luhmann 1998; 94). Tal como lo señalamos anteriormente, en el mundo, uno co-experimenta a cualquier persona de la misma manera formal, como otro yo (Luhmann 1996), en un mundo que se nos hace socialmente comprensible. Todos los objetos y los temas son relevantes tanto para alter como para ego ya que cada uno de nosotros (en un mundo familiar) tiene un horizonte de posibilidades, un potencial para aceptar una selección riesgosa y negar otras posibilidades.

En este sentido, la contingencia será como dice Niklas Luhmann (1990), el atributo principal de la sociedad para decidir no sólo frente a las posibilidades que se necesita seleccionar, sino también en cuanto a las probabilidades que se puedan cumplir en las decisiones tomadas:

"Un hecho es contingente cuando se le considera como una selección de entre otras posibilidades que, en algún sentido, siguen siendo posibilidades a pesar de la selección. Al implicar una potencia para la negación y la visibilidad de otras posibilidades, el concepto sólo puede aplicarse al sentido de la experiencia y de la acción subjetivas" (Luhmann 1998 16).

En mundo socialmente comprensible, la contingencia es subjetiva y universal a la vez (Luhmann 1998). Cada ego cuenta con un horizonte de posibilidades y debe relacionarse con la otra parte, quién también cuenta con la misma posibilidad, para seleccionar, con la posibilidad de negar opciones, y decidir qué puede ser más viable para reducir complejidad.

En el momento de actuar con "mi otro yo", habría una duplicación de alternativas en ambas partes que nos más que la doble contingencia. Talcott Parsons (1974) soluciona el problema de la doble contingencia a partir de su esquema medio/fines. Como sostiene Niklas Luhmann (2007), para Talcott Parsons, una acción se lleva a cabo cuando ya está establecida una diferencia entre medios y fines, es decir, cuando ya existe una concatenación de valores colectivos, que se hacen presentes en el momento en que el actor está decidido actuar. "Por ende, una colectividad funciona generalmente bajo el control de un gran número de normas particulares [...] Para institucionalizarse de una manera estable, las colectividades y los papeles deben regirse por normas y valores específicos" (Parsons 1974; 17). Las instituciones reproducirían normas y valores que permite que los individuos puedan alcanzar sus fines. La interacción social quedaría controlada por las normas y valores de la comunidad societal (Javala 2003).

Sin embargo, desde la perspectiva de la teoría de los sistemas sociales la duplicación de la contingencia es vista como "las posibilidades de negación que pueden retenerse y estabilizarse como posibilidades recíprocamente no actualizadas sino que implicadas. La duplicación de las contingencias es posible porque este potencial se localiza en los sujetos y los sujetos pueden experimentar otros sujetos" (Luhmann 1998; 17). Como lo señala Luhmann, esta duplicación comprende toda la estructura ya que existe el potencial generalizado para concebir hechos como selecciones que implican negaciones, para negar estas negaciones y para reconstruir otras posibilidades. Una selección implica negar otras posibilidades y por lo tanto, la negación es una potencia contenida en cualquier relación social.

Relacionando el problema de la dimensión social, la confianza viene a ser un prerrequisito para poder aceptar o rechazar el riesgo de que la otra parte cumpla con 
mis expectativas. Tanto "yo" como mi otro "yo" necesita solucionar un problema, en un presente, en una situación determinada, por lo que la confianza probabiliza una solución -con la posibilidad de negar una opción- que implica un riesgo en las relaciones sociales a las que nos enfrentamos para reducir complejidad:

"Primero que nada tiene que haber algún motivo para exponer la confianza. Tiene que haber alguna situación definida en que la persona que confía dependa de su socio; de otra manera el problema no se origina. Su comportamiento debe, entonces, comprometerlo con esta situación y hacerle correr el riesgo de que traicionen su confianza. En otras palabras debe invertir en lo que llamamos antes inversión riesgosa (Luhmann 1996; 73).

Como lo plantea Peter M. Blau en su estudio sobre el intercambio y el poder en la vida social, "el problema inicial consiste en demostrar que uno mismo es una persona digna de confianza [...] implica el riesgo de rechazo de la apertura por medio de la negativa a corresponder y a entrar en una relación" (Blau 1982; 82). La persona que otorga confianza corre con la posibilidad de no ser aceptado y si la persona que necesita de la confianza se arriesga y acepta el riesgo, "el éxito -si llega a aparecer- no aparece sino hasta después de la acción, mientras que debe haber un compromiso de antemano" (Luhmann $1996 ; 43$ ). Situación, motivación y riesgo potencian la negación y selección de otras posibilidades.

La confianza implica por lo tanto, tolerar la incertidumbre de que ese futuro, la aceptación del riesgo, se haga presente sabiendo que -si el éxito no llegó- tuvo la oportunidad de seleccionar otras posibilidades. Es una inversión riesgosa (Luhmann 1996), y por lo tanto, es lo que permite en un futuro negar otras posibilidades ya que si emerge una decepción, ésta se deposita en la historia como experiencia.

\section{La confianza Institucional:}

Confiar en las otras personas o en los demás sujetos individuales, ya no se concibe automáticamente como algo obvio (Luhmann 1996) y "como no se puede confiar en la gente, se confía en las instituciones como mediadores y generalizadores de la confianza" (Offe 1999; 73). Uno tiene que aprender a tolerar las diferentes formas de considerar el mundo y por lo tanto, uno tiene que aprender a confiar (Luhmann 1998) en las instituciones.

Las instituciones, son las que coordinan, conectan y reproducen a las diferentes comunicaciones especializadas como la económica, política, jurídica, científica, educativa o la de salud, con las demandas de los individuos (Offe 1999). Por lo tanto, son las que probabilizan la estabilidad social y regulan los riesgos de una sociedad compleja. Mientras el mundo sea cada vez más complejo y al mismo tiempo más susceptible de ser determinado por procesos contingentes (Luhmann 1996), las decepciones serán cada vez más visibles, por lo que las instituciones en la sociedad se harán cargo de éstas, tendrán la función de regular la incertidumbre, cumplir con las expectativas de los individuos y posibilitar el orden social.

Desde la perspectiva del programa funcionalista de la teoría de los sistemas sociales, las normas y valores que reproducen las instituciones orientan a las acciones y las vivencias de los individuos, pero éstas resultarían ser insuficiente para resolver, como hemos visto anteriormente, el problema de la doble contingencia (Luhmann 1998). Más bien, la conformidad como dice Claus Offe (1999), será contingente sobre la probabilidad que todo el mundo sea similarmente motivado a comprometerse con las 
instituciones. Por lo tanto, las reglas institucionales nunca pueden proveer a todas las contingencias y emergencias, éstas no son estáticas o eternas, sino contingentes e incompletas (Offe 1999).

La confianza institucional significaría entonces, en un nivel descriptivo, "conocer la idea básica o el bien de una institución" (Offe en Warren 1999; 6), de tal manera que a los sujetos individuales les haga sentido motivarse y comprometerse con las reglas, normas y valores que ellas ofrecen. Por lo tanto, la confianza institucional puede ser visto como un "amount to knowing that its constitutive rules, values, and norms are shared by participants and that they regard them as biding" (Offe en Warren 1999: 7). La confianza depende de que las instituciones tengan un repertorio de conocimientos de las diferentes normas o valores que son compartidos por los participantes tomando en cuenta la improbabilidad de que todos sean motivados a comprometerse.

Sin embargo, para que este nivel emerja, la confianza institucional depende de que las instituciones tengan la capacidad de reducir la complejidad y regular la incertidumbre de la sociedad. En este sentido, la confianza institucional resulta ser un tipo de "aspecto de legitimación" (Grosskopf 2002; 3) hacia las acciones de las instituciones que cumplen con las expectativas y garantizan la estabilidad de los sujetos individuales. Implica aceptar el riesgo para que el futuro se haga presente y se reduzca la posible decepción en las decisiones tomadas. Si las instituciones son efectivas, pueden transformar, las condiciones de emergencia en condiciones de persistencia (Luhmann 1996). Es decir, tienen la posibilidad de que el presente dure para futuras acciones, y abra nuevas perspectivas de futuro, para que las normas y los valores permanezcan en la comunicación:

"El autocompromiso con normas y valores es un aspecto intrínseco en la vida social. Pero este compromiso no se produce porque los hombres estimen la vida en el orden social y la honren con una especie de conceso constitucional. No existe tal contrato social, porque no existe la situación electiva presupuesta en el argumento. Pero existe [...] la necesidad de precisar tales generalizaciones donde se vuelvan riesgosas y susceptibles a la decepción. Sólo en este lugar teóricamente subordinado y ya no fundamental - encaja la función de la normatización. Se desarrollan normas en la medida en que se requieren generalizaciones que valgan ser afirmadas contrafácticamente (contra los hechos)" (Luhmann 1998; 297).

Las instituciones tienen que ser efectivas cuando se hacen cargo de las decepciones que emergen en una sociedad compleja. Estas experiencias se generalizan en la medida en que las instituciones cumplen con las expectativas de los individuos, lo cual permite que emerja la posibilidad de que se desarrollen normas y valores, que sean aceptados e integrados por los sujetos individuales. La socialización, por medio de las instituciones, no controla a la conciencia, únicamente motiva o estimula a cooperar y a comprometerse con ellas. La socialización sería más bien un tipo de auto-socialización que configura al sistema psíquico (Vanderstraeten 2000; Jalava, 2003) por lo que los sujetos individuales (en el aprendizaje) pueden aceptar o negar dependiendo de la oferta que se propone la institución a cumplir. Si las instituciones son eficaces para hacerse cargo de las decepciones, si se generalizan estas experiencias, se pueden desarrollar y estabilizar las normas y valores, ya que los sujetos individuales confían en sus instituciones. En este sentido, las instituciones dependen de la confianza ya que ésta es "central to maintenance of a society in operation since trust ensures cooperation though the reduction of uncertainty (Luhmann en Mitzal 1996: 250). Si no 
hay confianza, no hay ni cooperación ni compromiso para que se transformen las condiciones de emergencia en condiciones de persistencia (Luhmann 1996).

Al confiar en las instituciones, existiría un tipo de "libertad institucionalizada, es decir, la libertad coartada y moderada por el orden social; la libertad como un complejo de acciones o aspecto de acciones por los cuales uno es personalmente responsable" (Luhmann 1996; 69). Las instituciones no controlan nuestras expectativas pero sí motivan a aceptar el riesgo y a confiar en éstas, y así uno personalmente responsable por las acciones o las decisiones que uno toma.

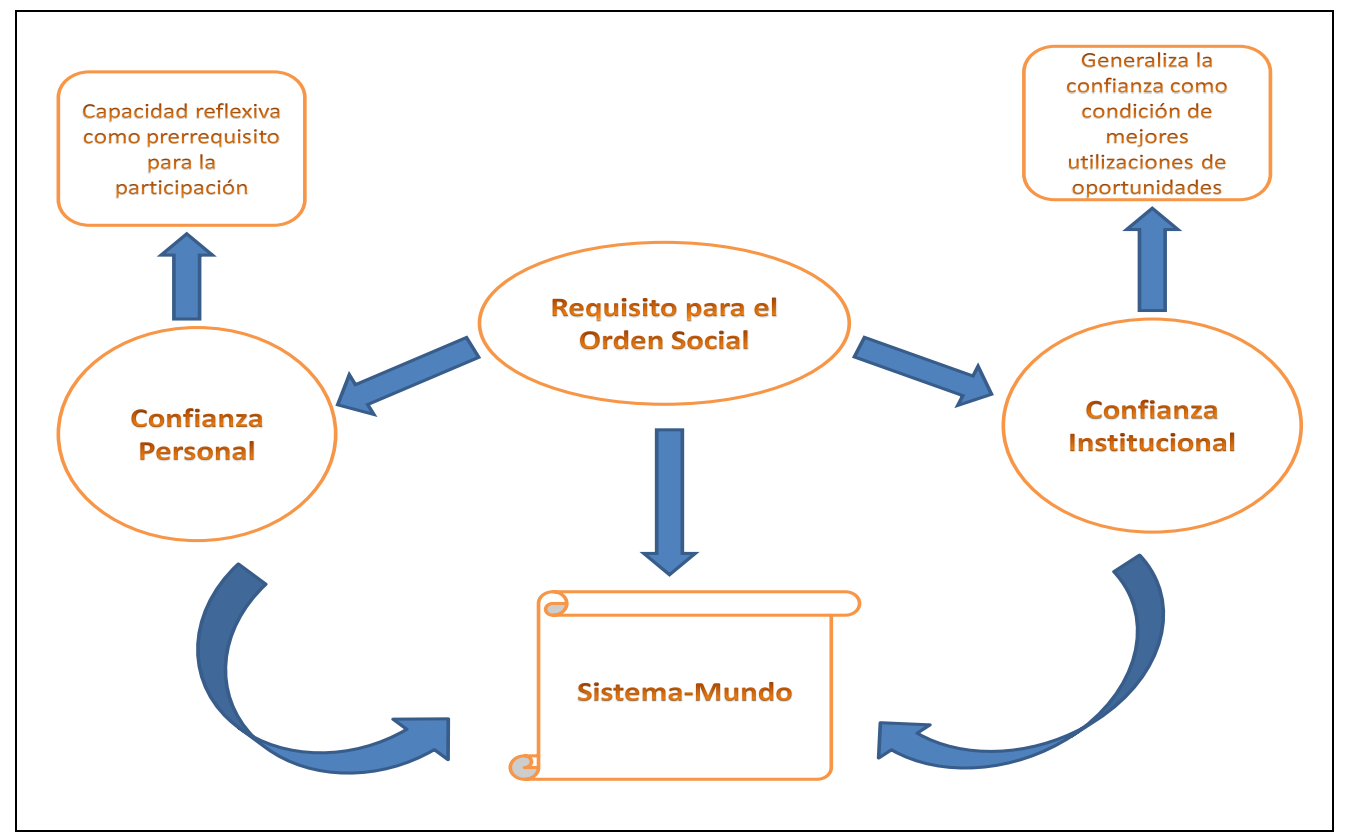

Fig. 1: La Confianza y el Orden Social.

Fuente: Elaboración propia

Por lo tanto, se admite que una sociedad necesita de las instituciones para garantizar un orden social. Pero también los sujetos individuales requieren de su capacidad reflexiva para aprender a confiar en éstos y tener la posibilidad de aceptar o rechazar una oferta comunicativa sin estar determinado por una concatenación de normas y valores ya puesta a priori para la acción. Más bien, la normatización emerge, pero se requiere de una generalización de los problemas que pueden ser solucionados por las instituciones, se requiere de los cálculos internos de los riesgos externos (conciencia) y de la solución a los problemas riesgosos (comunicación) para que se generalicen las normas. En este sentido, en la confianza personal y en la confianza institucional refleja la posibilidad de garantizar un orden social.

\section{Sistema Político, ideología y semántica}

El Sistema Político, así como el Sistema Económico, el Sistema de Derecho, el Sistema de la Ciencia, el Sistema Educativo, etc. es como menciona Bernard Barber (1983), uno de los mecanismos más importantes para la creación y mantenimiento de las expectativas públicas y de la estabilidad moral para el orden social. Para Danilo Zolo (1992) la función del Sistema Político, además de estabilizar las expectativas de las personas, es de seleccionar acciones que regulen los riesgos sociales en el sentido que "risks should be potentially covered and aborbed by the power structure" (Zolo 1992; 
40). En este sentido, si el sistema político logra regular los riesgos sociales y mantiene las expectativas públicas, se probabiliza que las selecciones realizadas por los que tienen el poder sean aceptadas.

Por lo tanto, la función del Sistema Político está en la capacidad de tomar decisiones que vinculen colectivamente (Luhmann 2004). Sin embargo, "la responsabilidad de la función debe quedar concentrada en algún lugar del Sistema Político y quien retoma esa responsabilidad es la organización denominada Estado" (Luhmann en Nafarrate 2004; 255). El Estado es el responsable del Sistema Político y tiene la función de regular los riesgos sociales y cumplir con las expectativas de los ciudadanos. "Se le atribuye la capacidad del Estado para responder en un territorio claramente delimitado a todos aquellos problemas que requerirían una respuesta centralizada del poder político" (Luhmann en Nafarrate, 2004: 141).

En la política, los valores o las normas se pueden ver reflejados en la ideología. Según Nicos Poulantzas (1979), la ideología no consistiría solamente, o simplemente en un sistema de ideas o de representaciones: concierne también una serie de prácticas materiales que se extienden en los hábitos, las costumbres o modos de vida, como materia vinculante en el conjunto de las prácticas sociales (Poulantzas 1979). Por lo tanto, la ideología implicaría que los individuos acepten un sistema de ideas o de representaciones para integrarlos en sus acciones y vivencias.

Para David Easton (1965), la ideología puede ser formulada como una pauta de objetivos que tiene la autoridad o un programa político que tiene el gobierno para tomar acciones en el presente para un futuro. Esta pauta de objetivos ayuda a que los miembros que acepten integrar la ideología, tengan esperanzas y aspiraciones. Es decir, la ideología ayudaría a que los individuos tomen decisiones seguras para el futuro, evaluando el pasado (Easton 1965):

"Legitimizing ideologies [...] consists of those principles and values validating a structure, its norms, and occupants in terms of images of future, interpretations of presents and conceptions of the past [...] Within the general set of belief prevalent in a system, we can expect to find convictions that express, as well reinforce, the sense of political unity among the members as a group a persons sharing a common set of structure, norms, values for political purposes" (Easton 1965; 336).

En este sentido, la ideología la podemos definir como un sistema de ideas y de prácticas materiales que se extienden en las prácticas sociales y que son formuladas bajo una pauta de objetivos que tiene la autoridad en su programa político. Con esto se generan expectativas en la sociedad. Es decir, la sociedad creen en las normas y valores presentes en la ideología y las integra en sus hábitos con la expectativa que el futuro les traerá mejores condiciones. Pero para lograr esta tarea, "each ideology may claim to repesent a comprehensive holistic system if it is sable to explain why competing ideologies exists" (Luhmann 1990; 129). Tiene que motivar a los sujetos individuales y convencerlos de que este programa ideológico es el más viable para orientar a sus vivencias y acciones. Y por lo tanto, "an ideology stabilizes itself by including its counter ideology into its system" (Luhmann 1990; 129). La ideología en este sentido se estabiliza en la medida en que logra introducir en su programa, no únicamente un sistema de normas valores que la autoridad busca cumplir. También, para que la sociedad pueda creer en las normas y en los valores, se tiene que integrar en su programa lo que no se debe creer. Como sostiene Bernard Barber (1983), la ideología contiene dos lados, uno positivo y uno negativo. El lado positivo justifica los 
valores de aquellos que creen en la ideología; el valor negativo critica aquellos que cree en otros valores. A través de la ideología;

"la sociedad puede definirse de la siguiente manera: "ella no es (todavía) lo que es; y sin embargo, es ya lo que todavía no es. La sociedad se encuentra en camino del progreso al cual hay que brindarle apoyo mediante liberalización; o reúne ya las fuerzas para la Revolución, al caer cada vez más profundamente en la crisis que la hará necesaria" (Luhmann 2007; 853).

Con la ideología se tiene la esperanza que el presente del futuro sirva como lugar determinado para el cumplimiento de la promesa de racionalidad. Posibilita refugiarse en un futuro todavía indeterminado (Luhmann 2007). Por lo tanto, para que una institución (el Estado por ejemplo) logre transformar sus condiciones de emergencia en condiciones de persistencia (Luhmann 1996), necesita primeramente construir confianza y cumplir con las expectativas de los individuos y reducir complejidad. Si la institución (el Estado) es exitosa para regular la incertidumbre, si genera expectativas positivas, la normatización se probabiliza y corre con la posibilidad de estabilizarse para que el presente dure para futuras acciones. Para que el presente del futuro, como mencionamos más arriba, sirva como lugar determinado para el cumplimiento de la promesa.

Relacionando la semántica con la ideología, ésta última proviene de una selección de textos, conceptos o comunicaciones que son reutilizables para proponer un programa político, con ellas se crean formas (socialismo o liberalismo), se crean pautas de objetivos o representaciones de ideas, con la intención de que sea aceptado por los individuos y lo integren en sus experiencias y acciones. Cuando "hablamos de semántica siempre que se trata de estas ventajas de sentido dignas de ser conservadas" (Luhmann 2007; 704). Como sostiene Niklas Luhmann (2007), la semántica es todo es todo lo que se produce como tema para la comunicación es por así decirlo, una reserva de temas que pueden ser reutilizables y pueden orientar a las distintas comunicaciones especializadas como la científica, jurídica, política, religiosa, etc.

En el caso de la política por ejemplo, los conceptos más conocidos que se han estado reutilizando a lo largo del tiempo y que orientan a los Estados en sus programas políticos ha sido el de paz, representación, nación, soberanía, democracia, estado de bienestar. En ellos podemos agregar los valores como libertad, igualdad, justicia o bien común. Cada uno de estos conceptos proviene de un contexto histórico que ha logrado mantenerse hasta la actualidad. "Si uno se fija en la terminología con la que se describe actualmente la política, inmediatamente se percibe lo envejecido de la conceptualización. En Europa, en la segunda mitad del siglo XVIII, la semántica de la política había sufrido un cambio total y desde entonces se conserva casi sin variaciones (Luhmann 2004; 321).

Como sostiene Niklas Luhmann (2004), el sistema político no necesita comenzar todo de nuevo, se puede remitir a una larga y conservada tradición y allí encontrarse así misma. Por lo tanto, las normas y valores que propone un gobierno puede venir cualquier contexto histórico cultural y de ahí, puede reutilizar esas comunicaciones para tratar de producir en el presente efectos deseados. 


\section{Procesos para la consolidación del proyecto bolivariano en los planos ideológico, político e institucional}

Ya que tenemos nuestra perspectiva teórica, es necesario caracterizar en el plano político-institucional, el modelo Estado/Gobierno que elabora el gobierno bolivariano desde la nueva constitución de 1999. Pero antes, describiremos los rasgos que caracteriza al sistema político venezolano antes de la entrada de las políticas neoliberales ya que, como veremos más adelante en la investigación, el Movimiento Bolivariano reutiliza muchos temas o comunicaciones de esta semántica del Sistema Político venezolano para proponer un proyecto alternativo al debilitamiento de las instituciones políticas. Con estos datos, partiremos hacia la descripción del proceso que se ha estado llevando a cabo para caracterizar la visión que se instala en el gobierno después de la aprobación del texto constitucional. De esta manera, podremos identificar lo que denominamos el reforzamiento ideológico. Podremos ir respondiendo a nuestra pregunta de investigación; ¿en qué medida el reforzamiento ideológico (El nuevo socialismo bolivariano del siglo XXI) facilita o debilita la posibilidad de producir confianza institucional?

\section{Venezuela y el debilitamiento del Estado Desarrollista:}

Con la llegada de la democracia con el Pacto de Punto Fijo en 1958 hasta la década de los 80, el Sistema Político venezolano se ha caracterizado por ser un Estado distribuidor a partir de la renta petrolera con una visión desarrollista. "Quien obtiene el poder sobre el Estado venezolano, obtiene la capacidad de decidir sobre la distribución del ingreso más importante de la economía. Por eso, en la historia contemporánea de Venezuela, política y petróleo (recepción y distribución de la renta) van de la mano" (Sosa en Mariñez 2000; 118). El petróleo vino a ser el principal recurso que utilizaron gobiernos para modernizar el país y mantener un equilibrio sociopolítico. No solamente tuvo la capacidad de distribuir sino que también tuvo un carácter regulador de las relaciones sociales.

Según el estudio realizado por Freddy Mariñez (2000), sobre la génesis del sistema político democrático venezolano, existen tres rasgos particulares que lo caracterizan antes de la década de los 90:

1.- El sistema político basó su estructuración sobre la coalición política de partidos. En este sentido, se estableció un acuerdo entre los partidos políticos puesto que el monopolio de la gestión pública era impuesto a ellos, subordinando a la sociedad civil (Mariñez 2000). "Desde los profesionales, como los médicos, educadores y hasta los campesinos y habitantes de los sectores más pobres, el control partidista orienta la actividades de la sociedad civil" (Gómez en Mariñez 2000; 117). El Estado a través de la coalición política de partidos, era capaz de ejercer un control sobre una sociedad que tenía una baja capacidad de auto-organización (Fleury 1999) en el contexto venezolano.

2.- Existía una alianza de elites: este sistema permitió garantizar a todo lo largo de su estructuración, a los sectores minoritarios pero poderosos que sus intereses no sean amenazados por aplicación de regla de la mayoría (Mariñez 2000). Por consecuencia, la toma de decisión se basó sobre la creación de un sistema de participación y representación semi-corporativo (Mariñez 2000). Es una representación semicorporativista ya que había alternancias en la toma de poder. Los partidos políticos de Acción Democrática y Copei eran quienes se hacían cargo de la organización estatal. Bajo esta representación semi-corporativista, el Estado fue capaz de crear un pacto 
con los distintos actores estratégicos para representar sus intereses, para que éstas no sean afectadas en las decisiones que toma el gobierno.

3.- Un último rasgo del sistema político en Venezuela viene a ser el clientelismo político: la organización estatal tenía que promover, financiar y guiar las actividades económicas y distribuir los recursos (Mariñez 2000) para mantener el equilibrio sociopolítico. El Estado venezolano como protector de la economía nacional tuvo un papel importante para proceso de desarrollo y la distribución de la renta.

De esta manera, los tres rasgos indican que la participación política en el contexto venezolano dependía de la distribución de la renta petrolera a través de la alianza de elites. Estos eran quienes tenían la capacidad de dirigir la toma de decisión y de regular la organización del Estado para mantener el equilibrio sociopolítico.

Bajo este contexto, el Estado desarrollista en la década de los años 60,70 y parte de los 80 "había movilizado a la sociedad alrededor de ideas y propuestas relativas a la construcción de una sociedad moderna [...] en un marco común de expectativas de las demandas sociales y de promesas de élites políticas de liderizar un orden donde las mayorías se sintieran incluidas" (Bermúdez 1998; 59). Tal como nos lo presenta la siguiente tabla, las distintas comunicaciones o temas de los programas políticos giraban en torno a un Estado que tuviese la capacidad de regular las relaciones sociales y de distribuir los recursos para garantizar la justicia social y el desarrollo:

\begin{tabular}{|c|}
\hline Policlasista \\
\hline Nacionalista \\
Desarrollista \\
\hline Valores: soberanía popular, justicia social, igualdad, acción humanista \\
\hline $\begin{array}{c}\text { Intervención legítima del Estado para limitar privilegios, garantizar la justicia social y } \\
\text { orientar actividad económica. Limitar la superpropiedad y proteger la pequeña propiedad } \\
\text { agrícola. }\end{array}$ \\
Cuadro 1: Caracterización Ideológica de los partidos políticos en el \\
Sistema Político Venezolano antes de los 90. \\
Fuente: Ana Irene Méndez 2006
\end{tabular}

Sin embargo, en la década de los 80 el Estado venezolano empieza a entrar en crisis. Cada vez más se le hizo difícil regular las relaciones sociales y distribuir los recursos a través de la renta petrolera. Como sostiene Freddy Mariñez (2000), en esta década el modelo económico construido a partir de la renta petrolera está en crisis producto de la crisis fiscal y un alto gasto público.

Como alternativa a este modelo de Estado se ingresa para el año 1989 una propuesta programática impuesta a la economía del mercado (Mariñez 2000). En el contexto latinoamericano, los gobiernos junto con las agencias multilaterales como el Banco Mundial (BM) o el Fondo Monetario Internacional (FMI) ejecutarán una serie de políticas bajo este paradigma. Su propuesta será, como mencionó Anthony Giddens (2002) de que, tanto el orden civil como el mercado, operen bajo sus propias dinámicas y prosperen a partir de la iniciativa individual para proporcionar un mejor bienestar a la sociedad. Por lo tanto, implicaba que la sociedad civil que estaba durante 50 años orientada por una coalición de partidos y por la renta petrolera, se adaptara a un modelo que promueve la iniciativa individual.

En este sentido, las condiciones de persistencia de las instituciones políticas que habían prevalecido desde que se instaló la democracia en 1958 con el pacto de Punto Fijo poco a poco irán perdiendo fuerza. Las normas y los valores presentes en el orden 
institucional eran aceptados por la población venezolana ya que el Estado era capaz regular los riesgos sociales y mantener las expectativas públicas a través de la renta petrolera y la coalición de las elites. Sin embargo, en la década de los 80 y 90, las instituciones políticas se irán debilitando. El sistema de valores propuesto por el Estado desarrollista, desde que se instala la democracia en 1958 no tuvo la capacidad de seleccionar nuevos presentes alternativos debido a la incapacidad de regular las decepciones que fueron emergiendo.

Hemos establecido en nuestro marco teórico que la semántica se relaciona con la ideología en el sentido de que ésta última proviene de una selección de textos, conceptos y comunicaciones que son reutilizables para proponer un programa político, o una representación de ideas con la intención de que sean aceptados por los individuos y lo integren en sus experiencias personales. Queríamos poner énfasis en este modelo de Estado desarrollista precisamente porque, el Movimiento Bolivariano, como veremos más adelante, reutiliza temas o comunicaciones referentes a la justicia social, a la renta petrolera y a la soberanía popular presentes en la semántica de la política venezolana. Buscará proponer un proyecto político alternativo al neoliberalismo y al debilitamiento del orden institucional tradicional.

\section{Visiones en la consolidación del proyecto bolivariano.}

Desde la llegada al poder del presidente Hugo Chávez Frías, muchos investigadores que estudian el proceso sociopolítico que se vive en el contexto venezolano, argumentan que con la Asamblea Constituyente que se llevó a cabo para la aprobación del texto constitucional, se observarán dos visiones que coexistirán acerca de las causas de los problemas del país y vías para solucionarlose (Maya 2004; Maingón y Cabezas 2008; D'Elia 2009).

A principios de la gestión del gobierno en 1998, se observaran distintos acontecimientos que poco a poco irán direccionando la manera de consolidar el proyecto político bolivariano. Según estos autores, las dos visiones que se observan para la consolidación del proyecto político poco a poco se irán confrontando ya que "parten de interpretaciones diferentes acerca de la realidad venezolana y postulan distintas formas de organización del Estado para superar los problemas que en ellos se observan" (D'Elia 2009). A medida que la gestión va avanzando, las diferencias se hicieron cada vez mayores (Cabezas 2008). Desde el año 2000 y hasta el año 2002, el gobierno dividió su gestión en dos frentes:

Las reformas democráticas progresistas o amplias buscaban recuperar y fortalecer las instituciones públicas como en la educación, la salud, la seguridad social, de manera equitativa y en el que el estado asuma su rol de ofrecer capacidad protectora ( $D^{\prime}$ 'Elia 2009). De igual manera, se buscaba la participación de los ciudadanos en la planificación, formulación y control de las políticas públicas, así como promoción de redes sociales para articular la labor de las organizaciones sociales (Sanjuán 2009).

Como sostiene Cabezas (2008) las reformas democráticas amplias buscaban superar los problemas de los sectores excluidos y hacerlos participar como sujetos de políticas públicas y sistemas de protección social en donde la institucionalidad del Estado deba avanzar hacia poderes públicos. De igual manera, buscaban que el Estado fuese el marco para democratizar las relaciones sociales intervenidas por los sectores políticos y económicos a través de la descentralización y la participación de los ciudadanos en la gestión pública (Cabezas 2008). Tal como lo caracterizamos en la primera parte de la 
investigación con la Agenda Alternativa Bolivariana, se seguirán estos lineamientos para que Estado tenga un papel más activo en la vida económica y social.

Bajo esta visión, en el año 2001, el gobierno aprobó el Primer Plan de Desarrollo Económico y Social 2001-2007. Este Plan buscaba llevar a cabo un programa de gobierno que garantizara lo contemplado en la Constitución de 1999:

"La Constitución de 1999 ayuda a caracterizar la acción social del Estado para la construcción de una ciudadanía de contenido social fundamentada en la universalidad de los derechos sociales, esenciales para elevar la calidad de vida, y en el reconocimiento de los sujetos de estos derechos sin ningún tipo de discriminación. La búsqueda de la equidad como objetivo supremo del ordenamiento económico y social, para hacer efectiva la universalización de los derechos y una justa distribución de la riqueza. El rescate de lo público como espacio para el ejercicio de una verdadera democracia que deberá sustentarse en la participación protagónica de todos en función del interés de todos" (D'Elia, 2002a)

Para poder cumplir con tales objetivos consagrados en la constitución de 1999, el Primer Plan de Desarrollo Económico y Social planteará 5 equilibrios: i) el equilibrio económico que buscaba fomentar el desarrollo productivo; ii)el equilibrio social que tenía como objetivo promover un mundo multipolar; iii) el equilibrio político que buscaba desarrollar una democracia participativa y protagónica; iv) el equilibrio territorial, que intentaba alcanzar una mayor justicia social; y v) el equilibro internacional que tenía por objetivo avanzar en la integración del territorio con fines de seguridad interna y protección de la soberanía nacional (Plan 2001-2007).

Esta visión seguirá los lineamientos de la Constitución de la República Bolivariana de Venezuela de 1999 para superar la exclusión y la desigualdad y garantizar los derechos sociales declarados en este texto Constitucional, actuando dentro del orden institucional, fortaleciéndolas y mejorándolas. Igualmente, dándoles a los ciudadanos la posibilidad de participar en la formulación, ejecución y control de la gestión pública.

Como sostiene Cabezas (2008), las reformas institucionales y los planes sectoriales no llegaron a concretarse plenamente (Cabezas 2008). Sobre ellos pesaron sus desacuerdos internos y dificultades financieras, la poca claridad de propósitos (D'Elia 2009) y en los criterios de implementación y la agudización de los conflictos entre el gobierno y los empresarios, gremios, organizaciones no gubernamentales, iglesias, autoridades locales y sectores políticos de la oposición (López Maya 2004).

"Antes del año 2001, los tiempos se consumieron en la redacción y aprobación de la nueva Constitución y en las sucesivas elecciones de autoridades públicas. Dentro del gobierno hubo tensiones entre posturas de reforma institucional que requerirían debates y negociaciones difíciles con la estructura burocrática, sindicatos, gremios y mandos operativos que señalaban la necesidad de dinamizar las políticas y los recursos para atender los sectores populares ( $D^{\prime} E l i a$ 2006).

Como veremos más abajo, la segunda visión, la revolución cívico-militar, poco a poco se irá posicionando en la gestión del gobierno ya que dinamizará las políticas sociales y los recursos para atender a los sectores populares (D'Elia 2006), debilitando la visión de las reformas amplia y dificultando la implementación de este Plan de Desarrollo Económico y Social. 
La revolución cívico-militar tenía como objetivo liberar a la sociedad venezolana de la influencia de los sectores económicos capitalistas (Cabezas 2008). Como veremos más adelante, esta visión actuaría fuera del orden institucional e iría desplazando de los espacios estratégicos a los poderes de la democracia tradicional (Elia 2009).

Esta visión empezó como menciona Cabezas (2009) con planes operativos asistenciales de instrumentación inmediata a través de una alianza cívico-militar para los sectores más necesitados. Esta visión cívico-militar aplicará varias estrategias a lo largo de su gestión, para poder consolidarla en la realidad venezolana. El lanzamiento de la Alianza Cívico Militar (2000); Plan Bolívar 2000 (2000-2001); La revolución desde Abajo (2003); La revolución dentro de la revolución (2004); El nuevo socialismo del siglo XXI (2006 en adelante).

Únicamente nos limitaremos a analizar dos estrategias que resultan fundamentales para nuestro objeto de estudio que tienen que ver con "La Revolución desde Abajo" y el Nuevo Socialismo del Siglo XXI.

\section{Revolución desde abajo}

Esta estrategia tenía la finalidad derrocar a los sectores de la oposición a través de una operación dirigida a masificar y hacer penetrar programas educativos, alimentarios y de salud en el tejido de los sectores populares (D'Elia 2009). Como mencionamos anteriormente, existía una agudización de los conflictos entre el gobierno y los empresarios, gremios, organizaciones no gubernamentales, iglesias, autoridades locales y sectores políticos de la oposición entre los años 2001 y 2002 (López Maya 2004), por lo que esta estrategia será una la manera de mantenerse y seguir consolidando el proyecto bolivariano. La revolución desde abajo se empieza desarrollar con el Convenio Cuba-Venezuela ${ }^{1}$ firmado desde el año 2000, y de aquí, emergen para el año 2003 y hasta la fecha ${ }^{2}$, las misiones sociales, apoyadas por contingentes militares, personal cubano y voluntarios comunitarios que lograron llegar a un porcentaje significativas de las zonas populares (D'Elia 2006).

Las misiones sociales empiezan a dar atención a los problemas prioritarios en el área de salud, alimentación, trabajo, educación y vivienda. Como sostiene el gobierno bolivariano, las misiones sociales "representan un gran esfuerzo dirigido hacia la cancelación de la deuda social con la población venezolana por décadas postergada y olvidada" (República Bolivariana de Venezuela 2009). Estas Misiones Sociales siguen teniendo un papel importante en la actualidad para atender las necesidades básicas como la salud, la educación o la vivienda. Tal como lo caracterizamos en el primer capítulo, los índices de pobreza, desempleo y acceso a los servicios públicos resultaron ser un factor decisivo para el debilitamiento de las instituciones políticas en el contexto venezolano:

"Amplios déficit de atención desde el punto de vista poblacional y territorial por efecto del debilitamiento, achicamiento, sesgo privado, fragmentación y desarticulación de los sistemas públicos [...] la existencia de amplios sectores de la población sin oportunidades de educación y trabajo [...] las crecientes desigualdades, a causa de un ejercicio oligárquico del poder en manos de ciertos grupos o sectores" (D’Elia 2006)

Se cree que el propósito de las misiones sociales será de preparar el camino para la sustitución del estado burocrático que se había heredado en la década de los 80 y 90 , 
por el Estado Revolucionario que esperaba constituirse (Cabezas 2008). Como sostiene Maingón (2009) la finalidad de las misiones sociales era "la des-burocratización de las relaciones gobierno-pueblo, la incorporación de las fuerzas armadas en los programas públicos, la organización social, política y económica de las comunidades, dentro de los valores colectivos, solidarios y humanos de la moral revolucionaria y el control y manejo y destino de recursos provenientes del petróleo" (Maingón 2009)

Se necesitará para tales objetivos, una nueva estructura administrativa, ya que se cree que estas misiones sociales fueron creadas para "saltar las estructuras ordinarias de la administración pública, logrando una dinámica de ejecución [...] dirigidas a eliminar las barreras de acceso de la gente (D'Elia 2006; 7). Tal como nos los presenta Francisco Cabezas (2009), esta estructura se puede observar en el siguiente cuadro:

\begin{tabular}{|c|}
\hline Presidente de la República: \\
\hline $\begin{array}{c}\text { Designa Comisión Presidencial para la Misión: integrado generalmente por el Ministerio o Instituto } \\
\text { Público Líder, organismos Públicos Voluntariados, Fuerzas Armadas, PDVSA, Ministerios de Organizaciones } \\
\text { de la Revolución }\end{array}$ \\
\hline $\begin{array}{c}\text { Decreta Presupuestos extraordinarios: Decreto de leyes aprobadas por la Asamblea Nacional con } \\
\text { cargo a recursos de fondos que se alimentan de PDVSA y reservas internacionales. }\end{array}$ \\
\hline Crea Fundaciones: órganos administrativos adscritos generalmente al Ministerio o al Instituto Público \\
Líder de la Comisión. \\
Cuadro 2: Estructura Administrativa de las Misiones Sociales \\
Fuente: Cabezas 2009
\end{tabular}

Yolanda D’Elia (2006), señala que las Misiones se desarrollaron a través de instancias de coordinación ad hoc designadas por el presidente, que permiten organizar la estructura institucional alrededor de la agenda de cada misión y, asignar recursos, cuyo manejo también debía ser realizado por una vía extrapresupuestaria, con la finalidad de cumplir con los objetivos de la estrategia (D'Elia 2006). A partir de planes de presupuestarios extraordinarios provenientes de los recursos de Petróleos de Venezuela (PDVSA), se empieza a observar la posibilidad de crear una nueva institucionalidad, separada del sistema público existente, para atender a los sectores excluidos y consolidar en un interior los valores y símbolos de la revolución (Cabezas 2008), y todo esto, como sostuvo Hugo Chávez, "gracias al control que ahora si tenemos sobre PDVSA y a la distribución equitativa de esos ingresos, tenemos recursos disponibles con planes extraordinarios" (Chávez Hugo 2004).

La consolidación del proyecto bolivariano se verá no únicamente en el acceso a la salud, sino también en la vivienda o en la educación hacia los sectores más vulnerables. A partir de una comisión presidencial integrada por varios agentes y a partir de planes extrapresupuestario decretados por el presidente de la república a través de los recursos petroleros se pueden lograr tales metas. En estas misiones, se observará también una participación y apoyo por parte de Cuba, las instituciones militares de la Fuerza Armada venezolana y la sociedad civil que apoya las intenciones del gobierno.

\section{EI socialismo bolivariano en el plano político-institucional:}

Desde el año 2004 el presidente había anunciado que el rumbo definitivo de la revolución era el Nuevo Socialismo del siglo XXI (D'Elia 2009). Como sostiene la Alianza Bolivariana del Poder Popular (2008), el nuevo socialismo del siglo XXI no trata de perfeccionar el estado actual, sino que el nuevo estado tiene que ser otro, "que por su esencia, estructura y forma permita participar directamente al conjunto de la 
sociedad en la administración del poder socializado" (Alianza Bolivariana del poder popular 2008). Como señala Ana María Sanjuán (2009), de esta fecha al 2008, se seguirán creando misiones sociales - Misión Alma Mater, Misión 13 de abril, y Misión Che Guevara - (San Juan 2009) con el fin de formar en la ideología socialista y ensayar la construcción de ciudades socialistas (D'Elia 2009). Las estrategias mencionadas anteriormente - Plan Bolívar 2000, Alianza Cívico Militar, Revolución desde Abajo y Revolución dentro de la Revolución - le dará al gobierno la oportunidad de consolidar su proyecto político bajo su slogan; "el nuevo socialismo del siglo XXI".

Un primer elemento que se instala en esta estrategia en la creación de un partido político socialista, el Partido Socialista Unido del Venezuela. Es un partido político integrada por agentes sociales y políticos que apoyan a la Revolución Bolivariana. Se aspira que todos los que apoyen a la revolución se inscriban en este partido político para formar un frente socialista y unido. Según los datos proporcionados por el blogspot del PSUV, para el año 2007, más de 3 millones 200 mil venezolanos se han registrado como aspirantes a militantes del Partido Socialista Unido de Venezuela (PSUV 2007).

Los objetivos del El Partido Socialista Unido de Venezuela son de "conocer, percibir y propiciar las ideas, el debate y la participación protagónica de las experiencias políticas social de las organizaciones populares, sociales, culturales, militares y políticas; para acordar lineamientos comunes que fortalezcan la integración de este partido" (PSUV 2007).

De igual manera, para consolidar el nuevo socialismo bolivariano se crea la ley de los consejos comunales que establece reglas de organización y funcionamiento de estos consejos (Romero 2007). Su base constitucional de esta nueva ley se basa fundamentalmente en la ley de los Consejos Local de Planificación Pública sancionada en el año $2002^{3}$ y mencionada anteriormente. Será ella donde se mencionará por primera vez en nuestra legislación a los consejos comunales como canal para la participación popular (Romero 2007). Estos consejos comunales tendrán como objetivo regular la participación ciudadana en materia de formulación, ejecución y control de políticas públicas (Romero 2007). Su estructura organizacional, está básicamente integrada por cuatro órganos; "La Asamblea de Ciudadanos, como máxima instancia del poder, el Órgano ejecutivo, como el cuerpo de Voceros y Voceras, La Unidad de gestión financiera o también llamado Banco Comunal y la Unidad de Contraloría Social.

\section{La reforma constitucional y el nuevo socialismo del siglo XXI:}

El presidente de la República lanzará para el año 2007 una propuesta de reforma constitucional cuyo propósito será de profundizar sobre la consolidación del proyecto bolivariano y construir un nuevo orden político y social bajo el lema del nuevo socialismo bolivariano del siglo XXI. Cabe detenernos a describir esta propuesta de reforma ya que aquí es donde se ve reflejado la intención y la posibilidad que tiene el gobierno para instalar esta propuesta en el contexto venezolano.

La propuesta de reforma constitucional intentaba modificar 33 artículos estratégicos de la constitución. Como lo señala Rita Giacalone (2007), entre los 33 artículos:

"Los aspectos políticos centrales eran la reelección indefinida del presidente no así de los otros cargos electivos -, la extensión del período presidencial a siete años (Artículo 230), el cambio de sistema electoral del sistema mixto - 
que otorga $60 \%$ de representación a la mayoría y $40 \%$ de representación a las minorías - a un sistema mayoritario estricto (Álvarez 2007: 278) y la rebaja de la edad para votar de 18 a 16 años (Artículo 64)" (Giacalone Rita 2007; 14).

En lo que respecta al periodo presidencial, el artículo 230 de la Constitución de 1999 plantea que "el periodo presidencial es de seis años. El presidente de la República puede ser reelegido y de inmediato por una sola vez, para un nuevo periodo" (Constitución de 1999). Sin embargo, la propuesta modificaría el artículo de la siguiente manera; "el periodo presidencial es de siete años. El presidente puede ser reelegido o reelegida" (Gobierno Bolivariano de Venezuela 2007), por lo que el presidente de la república puede reelegirse en cualquier periodo presidencial ya que no se especifica por cuántas veces.

Otro punto importante de la reforma constitucional tiene que ver con la creación del poder comunal, éste le reducía la autonomía de los alcaldes y de los gobernadores. Tal como lo plantea un documento llamado los 5 motores constituyentes, documento del gobierno que representa los cambios que se desean para llegar al nuevo socialismo del siglo XXI, se plantea lo siguiente:

En este sentido, el poder comunal atribuía a los consejos comunales, mencionados anteriormente, la misión de sustituir "el viejo Estado burgués por un Estado revolucionario, controlando a las autoridades locales y regionales electas" (Giacalone Rita en Álvarez 2007; 15). De igual manera, la propuesta creaba una nueva figura de organización territorial, las ciudades comunales, las cuales tenían la intención de eliminar a los municipios y a las parroquias. Según Rita Giacanole (2007), esta entraría en contradicción con los municipios ya que se crearía un solapamiento de funciones entre ambas figuras y quedar vinculadas esas ciudades al poder nacional (Giacalone 2007).

Otro cambio que planteaba la reforma constitucional era la eliminación de la autonomía del Banco Central de Venezuela. Según el artículo 319 de la constitución se plantea que "las competencias monetarias del Poder Nacional serán ejercidas de manera exclusiva y obligatoria por el Banco Central del Venezuela [...] El banco Central de Venezuela persona jurídica de derecho público con autonomía para la formulación y el ejercicio de las políticas de su competencia..." (Constitución de 1999).

Sin embargo, la propuesta de reforma constitucional menciona que el "sistema monetario nacional debe propender al logro de los fines esenciales del Estado Socialista y el bienestar del pueblo por encima de cualquier otra consideración. El poder ejecutivo, a través del banco Central, en estricta y obligatoria coordinación, fijará las políticas monetarias y ejercerá las competencias monetarias del Poder Nacional" (Gobierno Bolivariano de Venezuela 2007). El poder ejecutivo es quien tomaría las decisiones convenientes a través del Banco Central para fijar políticas monetarias.

Otro artículo importante que cabe mencionar es el artículo 115 ya que reduce el derecho de propiedad o la promoción de la iniciativa privada por una nueva forma de propiedad socialista: 


\begin{tabular}{|c|c|}
\hline Vigente & Reforma \\
\hline $\begin{array}{l}\text { Artículo 115: Se garantiza el derecho de } \\
\text { propiedad. Toda persona tiene derecho al uso, } \\
\text { goce, disfrute y disposición de sus bienes. La } \\
\text { propiedad estará sometida a las } \\
\text { contribuciones, restricciones y obligaciones } \\
\text { que establezca la ley con fines de utilidad } \\
\text { pública o de interés general. }\end{array}$ & $\begin{array}{l}\text { Artículo 115: Se reconocen y garantizan las diferentes } \\
\text { formas de propiedad. La propiedad pública es aquella que } \\
\text { pertenece a los entes del Estado; la propiedad social es } \\
\text { aquella que pertenece al pueblo en su conjunto y las } \\
\text { futuras generaciones, y podrá ser de dos tipos: la } \\
\text { propiedad social indirecta, cuando es ejercida por el } \\
\text { Estado a nombre de la comunidad, y la propiedad social } \\
\text { directa, cuando el Estado la asigna, bajo distintas formas } \\
\text { y en ámbitos territoriales demarcados, a una o varias } \\
\text { comunidades, a una o varias comunas, constituyéndose } \\
\text { así en propiedad } \\
\text { comunal o a una o varias ciudades, constituyéndose así } \\
\text { en propiedad ciudadana; la propiedad colectiva es la } \\
\text { perteneciente a grupos sociales o personas, para su } \\
\text { aprovechamiento, uso o goce en común, pudiendo ser de } \\
\text { origen social o de origen privado; La propiedad mixta es } \\
\text { la conformada entre el sector público, el sector social, el } \\
\text { sector colectivo y el sector privado, en distintas } \\
\text { combinaciones, para el aprovechamiento de recursos o } \\
\text { ejecución de actividades, siempre sometida al respeto } \\
\text { absoluto de la soberanía económica y social de la nación; } \\
\text { y la propiedad privada es aquella que pertenece a } \\
\text { personas naturales o jurídicas y que se reconoce sobre } \\
\text { bienes de uso y consumo, y medios de producción } \\
\text { legítimamente adquiridos. }\end{array}$ \\
\hline $\begin{array}{l}\text { Fuente: Constitución de la República } \\
\text { Bolivariana de Venezuela, } 1999 .\end{array}$ & Fuente: Gobierno Bolivariano de Venezuela, 2007. \\
\hline
\end{tabular}

Cuadro 3: Propuesta de Reforma Constitucional: Propiedad Social

Uno de los puntos fundamentales de la constitución que se aprobó en 1999 tiene que ver con la descentralización del poder nacional hacia los poderes estatales, municipales y locales. Sin embargo, con la nueva propuesta se observa que el poder nacional es el que promueve la participación y la creación de mejores condiciones de vida para los ciudadanos para construir una democracia socialista.

Como sostiene Francisco Cabezas (2008), la propuesta de reforma cambia el concepto público de la administración del Estado, colocando sus instituciones bajo el mando de los órganos del poder revolucionario y a los órganos de gobierno bajo el control de las instituciones y las leyes. De igual manera, "eleva las misiones a una categoría especial de administración en la que pueden experimentarse tanto nuevos sistemas de programas o servicios como normas, leyes y pautas de organización territorial, social y económica, a voluntad del Poder Ejecutivo" (Cabezas Luis Francisco 2008: 8). Esto se puede ver reflejado en los siguientes artículos que presentamos a continuación:

\begin{tabular}{|l|l|}
\hline Vigente: & Reforma: \\
\hline $\begin{array}{l}\text { Artículo 158: La descentralización, como política } \\
\text { nacional, debe profundizar la democracia, } \\
\text { acercando el poder de la población y creando las } \\
\text { mejores condiciones, tanto para el ejercicio de la } \\
\text { democracia como para la presentación eficaz y } \\
\text { eficiente de los cometido estadales. }\end{array}$ & $\begin{array}{l}\text { Artículo 158: El Estado promoverá como política } \\
\text { nacional, la participación protagónica del pueblo, } \\
\text { restituyendo el poder y creando las mejores } \\
\text { Socialista. }\end{array}$ \\
\hline $\begin{array}{l}\text { Artículo 300: La ley nacional establecerá las } \\
\text { condiciones para la creación de entidades } \\
\text { funcionalmente descentralizadas para la realización } \\
\text { de actividades sociales y empresariales, con el } \\
\text { objeto de asegurar la razonable productividad } \\
\text { económica y social de los recursos públicos que en } \\
\text { ella se invierte. }\end{array}$ & $\begin{array}{l}\text { Artículo 300: La ley nacional establecerá las } \\
\text { entidades regionales, para la promoción y realización } \\
\text { de lactividades económicas o sociales bajo, principios }\end{array}$ \\
$\begin{array}{l}\text { decanismos de control y fiscalización que aseguren } \\
\text { la transparencia en el manejo de los recursos } \\
\text { públicos que en ellas se inviertan, y su razonable }\end{array}$ \\
\hline
\end{tabular}




\begin{tabular}{|l|l|}
\hline Vigente: & Reforma: \\
\hline $\begin{array}{l}\text { Artículo 321: Se establecerá por ley un fondo de } \\
\text { estabilización macroeconómica destinado a } \\
\text { garantizar la estabilidad de los gastos del Estado en }\end{array}$ & $\begin{array}{l}\text { Artículo 321: En el marco de su función de } \\
\text { administración de las reservas internacionales, el } \\
\text { Jefe del Estado establecerá, en coordinación con el }\end{array}$ \\
$\begin{array}{l}\text { los niveles municipal, regional y nacional, ante las } \\
\text { fluctuaciones de los ingresos ordinarios. Las reglas } \\
\text { de funcionamiento del fondo tendrán como } \\
\text { principios básicos la eficiencia, la equidad y la no } \\
\text { nivel de las reservas necesarias para la economía } \\
\text { nascriminación entre las entidades públicas que } \\
\text { aporten recurso al mismo. }\end{array}$ & $\begin{array}{l}\text { excedentarias, las cuales se destinarán a fondos que } \\
\text { disponga el Ejecutivo Nacional para inversión } \\
\text { productiva, desarrollo e infraestructura, } \\
\text { financiamiento de las misiones y, en definitiva, el } \\
\text { desarrollo integral, endógeno, humanista y socialista }\end{array}$ \\
de la nación.
\end{tabular}

Se observa que el contenido de los artículos enfatiza sobre el hecho que es el nuevo socialismo del siglo XXI la propuesta que se quiere lograr, y en ella, el poder comunal coordinado con el poder nacional resulta de suma importancia para instalar en las acciones y vivencias de la población venezolana este programa político.

Otros elementos importantes que cabe señalar tiene que ver con el cambio de nombre de la Fuerza Armada Nacional por el de la Fuerza Armada bolivariana. Como sostiene Rita Giacone (2007), se le atribuyó a la FAB "la planificación y ejecución de la doctrina militar bolivariana" (Giacone Rita en Anteproyecto de Reforma Constitucional presentado por el Presidente de la República Bolivariana de Venezuela, Hugo Rafael Chávez Frías" en www.eluniversal.com 2007).

Por lo tanto, esta propuesta de reforma constitucional buscaba la conformación de un poder político cívico militar centralizado (Cabezas 2008), el desarrollo de un sistema económico estatizado, en el cual la propiedad colectiva tenga mayor peso que la propiedad privada (Sanjuán 2009) y la integración de una nueva estructura socioterritorial, con autoridades regionales, militares, económicas y comunales, las cuales estarían subordinadas al poder central, serían evaluadas según la disciplina y valores socialistas (D'Elia 2009). Para Rita Giacone la reforma constitucional se enfocó es 5 aspectos estratégicos:

"La reelección presidencial continua; 2) la eliminación de la descentralización; 3) el ataque a la propiedad privada; 4) la subordinación de la FAN a un proyecto político (Quirós Corradi 2007) y 5) la "constitucionalización" del socialismo (Giacone Rita 2007; 18)".

Para el 2 de diciembre del año 2007, se llevó a cabo el referéndum. Como menciona el Centro Nacional Electoral (CNE), la reforma constitucional fue rechazada con un $51.01 \%$ que representa 4.539 .707 votos contra un $48.99 \%$ que representa 4.360 .014 votos. De igual manera, hubo una abstención de $44.11 \%$ que representan 7.107 .225 votos. Como lo señala Rita Giaconne:

"La desagregación de estos resultados globales muestra algunos elementos interesantes: 1) el No ganó en siete de los ocho estados más importantes de Venezuela; 2) en la votación el gobierno perdió cerca del $40 \%$ de los votos alcanzados en la elección presidencial de diciembre de 2006 (7.300.000), al obtener sólo unos $4.300 .000 ; 3$ ) esos votos no migraron hacia la oposición -- 
que aumentó sólo en 5 \% sus votos con respecto al año anterior --, sino que se manifestaron bajo la forma de la abstención (44 \%) (Martínez 2007); y 4) ésta fue mayor en las zonas populares que en las de clase media y alta (Cañizalez 2007)" (Giacalone Rita 2007; 16).

Muchas críticas se observaron a esta reforma constitucional. Por ejemplo, el Partido Comunista de Venezuela (PCV) "hizo observaciones de fondo, al señalar que la caracterización del actual Estado venezolano [como socialista] no es posible todavía, solicitando también que se mantuviera la prohibición de que las asociaciones políticas contrataran con entidades del sector público y difiriendo de considerar al Poder Popular (Gianconne Rita 2007; 17). En las fuerza Armadas, el ex ministro de la defensa - ex miembro del MBR-200- criticó a las intenciones del gobierno y llamó públicamente a votar en contra de la propuesta de reforma constitucional. Su argumento fue que lo planteado era una transformación del Estado en un diferentísimo modelo de país, quitándole poder al pueblo. Agregó que se utilizaba en forma genérica el término socialista, sin indicar claramente a que se refiere este término (Giaconne Rita en AFP."Chávez califica de traición cuestionamientos de ex ministro de Defensa" 6 de noviembre de 2007).

\section{Análisis del cambio hacia el Nuevo Socialismo Bolivariano del Siglo XXI.}

Tal como lo observamos en la segunda parte de la investigación, el gobierno bolivariano reutiliza -además de los personajes históricos que representan el rescate de lo propio y lo popular- varios elementos de los Estados Desarrollistas antes de los 80 para proponer un programa político de transformación, un nuevo modelo de Estado/gobierno de carácter Socialista.

Desde que se propone la Agenda Alternativa Bolivariana, las comunicaciones giran en torno a la recuperación de un papel del Estado que tenga la capacidad de regular y proteger las distintas áreas estratégicas de la economía nacional y fortalecer a las instituciones públicas para que se ejerza lo consagrado en la Nueva Constitución de 1999. Sin embargo, se empieza también a observar una comunicación que gira en torno a una nueva administración que busca remplazar a las instituciones tradicionales. A medida que la gestión va avanzando las diferencias se hace cada vez mayores entre las dos visiones, y para el año 2004 se da paso a una Semántica Socialista.

\begin{tabular}{|l|l|}
\hline Reforma Sociales Amplias. & $\begin{array}{l}\text { Revolución Cívico-Militar: hacia el Estado } \\
\text { Socialista }\end{array}$ \\
\hline $\begin{array}{l}\text { Sistemas excluyentes por fuerza de pactos } \\
\text { entre partidos políticos y elites gobernantes }\end{array}$ & $\begin{array}{l}\text { Sistemas excluyentes por fuerza de oligarquías } \\
\text { nacionales y extranjeras apoderadas del Estado }\end{array}$ \\
\hline $\begin{array}{l}\text { Sectores excluidos (pobres, trabajadores } \\
\text { informales, mujeres)deben ser principales } \\
\text { sujetos de políticas públicas y de sistema de } \\
\text { protección social }\end{array}$ & $\begin{array}{l}\text { Sectores populares y fuerzas armadas son un mismo } \\
\text { pueblo que deben organizarse para tomar la conducción } \\
\text { del Estado }\end{array}$ \\
\hline $\begin{array}{l}\text { Estado como marco para democratizar las } \\
\text { relaciones sociales intervenidas por los sectores } \\
\text { políticos y económicos. }\end{array}$ & $\begin{array}{l}\text { Estado como instrumento para liberar a la sociedad de } \\
\text { la influencia de los sectores capitalistas, a través de la } \\
\text { colectivización de los medios económicos, políticos y } \\
\text { culturales }\end{array}$ \\
\hline \multicolumn{2}{|c|}{ Cuadro 5: Visiones en el Gobierno Bolivariano } \\
Fuente: Cabezas 2009
\end{tabular}

Se pueden visualizar varios problemas que inciden en el debilitamiento de la visión de las reformas amplias y en la emergencia de una visión cívico-militar rumbo al Nuevo Socialismo del Siglo XXI. Tomemos como ejemplo, la economía y la política: 


\begin{tabular}{|l|l|l|}
\hline Riesgo & Política & Economía \\
\hline Interno & $\begin{array}{l}\text { En el gobierno: desacuerdos sobre la toma } \\
\text { decisión y en la forma de llevar a cabo } \\
\text { las acciones. }\end{array}$ & $\begin{array}{l}\text { Dificultades económicas para llevar a } \\
\text { cabo las acciones. }\end{array}$ \\
\hline Externo & Gobierno/oposición (poder) & Ganancia/perdida (dinero) \\
\hline \multicolumn{2}{|c|}{ Cuadro 6: Problema con la reformas amplias } \\
Fuente: Elaboración Propia
\end{tabular}

En la política existían distintos desacuerdos en la manera de llevar a cabo las acciones. Ya hemos dado los ejemplos entre la visión reformista y la visión cívico militar. Pero también, la oposición dominante se había caracterizado orientarse a un programa de valores que era diferente a la del gobierno bolivariano. "En el caso de los valores las preferencias se estilizan normativamente para remarcar la capacidad de enlace intersubjetivo y la preservación de su validez aun en caso de desengaño" (Luhmann 2004; 207). La preservación de su validez dependía de la alianza de elites y de la coalición de partidos que lo caracterizaban desde que llega la democracia en 1958.

También se observan desacuerdos con el sector privado ya que éstos no querían aceptar el riesgo de un proyecto político que critica justamente el apoyo a las minorías poderosas y a la iniciativa privada.

En otras palabras, implica tiempo para que los distintos actores estratégicos en el contexto venezolano se pongan de acuerdo y se comprometan con un programa político para llevar a cabo lo propuesto en la visión de las reformas amplias. Implica tiempo para que las instituciones tradicionales se pongan en marcha y empiecen a traer resultados efectivos para que se generalicen las expectativas y para que el gobierno pueda seguir en el poder.

Por lo tanto, la visión cívico-militar emerge una vez que ha podido procesar los problemas básicos de exclusión social en poco tiempo y con una relación directa con el pueblo a través de una nueva estructura administrativa. Pareciera que ahora con este cambio, se establece un tipo de proyecto de carácter corporativista estatal. A diferencia del corporativismo social que se caracteriza por un surgimiento más o menos autónomo de las organizaciones que buscan una concertación con el poder público, el corporativismo estatal se refiere a un control del Estado sobre las organizaciones con el objeto de mantenerlas sobre su dominio (Medina 2003).

Como sostiene Camacho, "el corporativismo, como política gubernamental, proviene de una orientación ideológica estatista y se ejecuta en la forma de decisiones que buscan la fragmentación de las clases sociales con el propósito de facilitar el predominio estatal y disminuir la fuerza y los proyectos de la sociedad civil" (Camacho en Medina, 2003; 17). Se avanza hacia un estado en que "las unidades constitutivas están organizadas de forma no competitiva, jerárquicamente ordenadas y funcionalmente diferenciadas, habiendo recibido del Estado, que ejerce sobre ellas un elevado nivel de control" (Schmitter en Fleury 1999; 160). Se rechazaría por lo tanto, no sólo la autonomía de las organizaciones, sino también la competencia y el individualismo característico del capitalismo.

Resulta interesante observar el proceso que han vivido los modelos Estado/Gobierno que ha vivido el sistema político venezolano para observar los distintos temas que son reutilizados por el gobierno bolivariano: 
La confianza institucional y el proyecto bolivariano en el contexto Venezolano

\begin{tabular}{|c|c|c|}
\hline Estado Distribuidor & Estado Social de Derecho & Estado Socialista \\
\hline Democracia Representativa & Democracia Participativa & Democracia Socialista \\
\hline $\begin{array}{l}\text { Coalición de Partidos } \\
\text { (semi-corporativo) }\end{array}$ & Participación Ciudadana & Corporativismo Estatal \\
\hline Alianza de elites & Apoyo a las mayorías & Apoyo a las mayorías \\
\hline Clientelismo Político & Clientelismo Político & Clientelismo Político \\
\hline
\end{tabular}

En los tres modelos el Estado se describe asimismo como el protector de la economía nacional que tiene la capacidad de promover, financiar y guiar las actividades económicas y distribuir los recursos (Mariñez 2000) para mantener el equilibrio sociopolítico a través de la renta petrolera. Sin embargo, en el Estado Social de Derecho el modelo de desarrollo está basado en una economía más humanista, autogestionaria y competitiva, con una apertura comercial, mientras que en el Nuevo Socialismo Bolivariano del Siglo XXI, la economía mixta sería remplazada por una economía socialista en el que la organización estatal es quien controlaría jerárquicamente desde arriba los sectores estratégicos para distribuir los recursos y proteger la economía nacional.

En el segundo caso, la alianza de élites es remplazada en el Estado Social de Derecho y en el Estado Socialista por un apoyo a la mayoría. Es decir, ya no se representan a los intereses de la minoría, más bien, el Estado y sus instituciones se comprometen a tomar decisiones para garantizar los derechos sociales y económicos, mantener la igualdad y la justicia social. Se reemplaza la alianza de élites que representaba los intereses de una minoría por el de una mayoría.

Por último, el partido político ya no controla o subordina a los distintos actores o integrantes de la sociedad civil, más bien, en el Estado Social de Derecho, se promueve la autonomía de las organizaciones o la participación ciudadana en los espacios públicos. Sin embargo, en el Estado Socialista prevalecería un tipo de corporativismo Estatal que tiene la capacidad de controlar y dirigir a las organizaciones, negando así la autonomía de éstas.

En este sentido, pareciera que el Nuevo Socialismo Bolivariano del Siglo XXI promueve un orden corporativista bajo una semántica socialista precisamente porque su estructura administrativa permite agilizar los programas sociales para resolver los problemas de los sectores más vulnerables desde un Estado que regula y controla. Implicaría que los sujetos individuales acepten esta comunicación política y confíen ya que se les está solucionando un problema específico de riesgo, que, si hubiese pasado por las instituciones tradicionales, hubiese implicado tiempo para que se generalicen las expectativas e integren en sus prácticas sociales estos valores revolucionarios. 


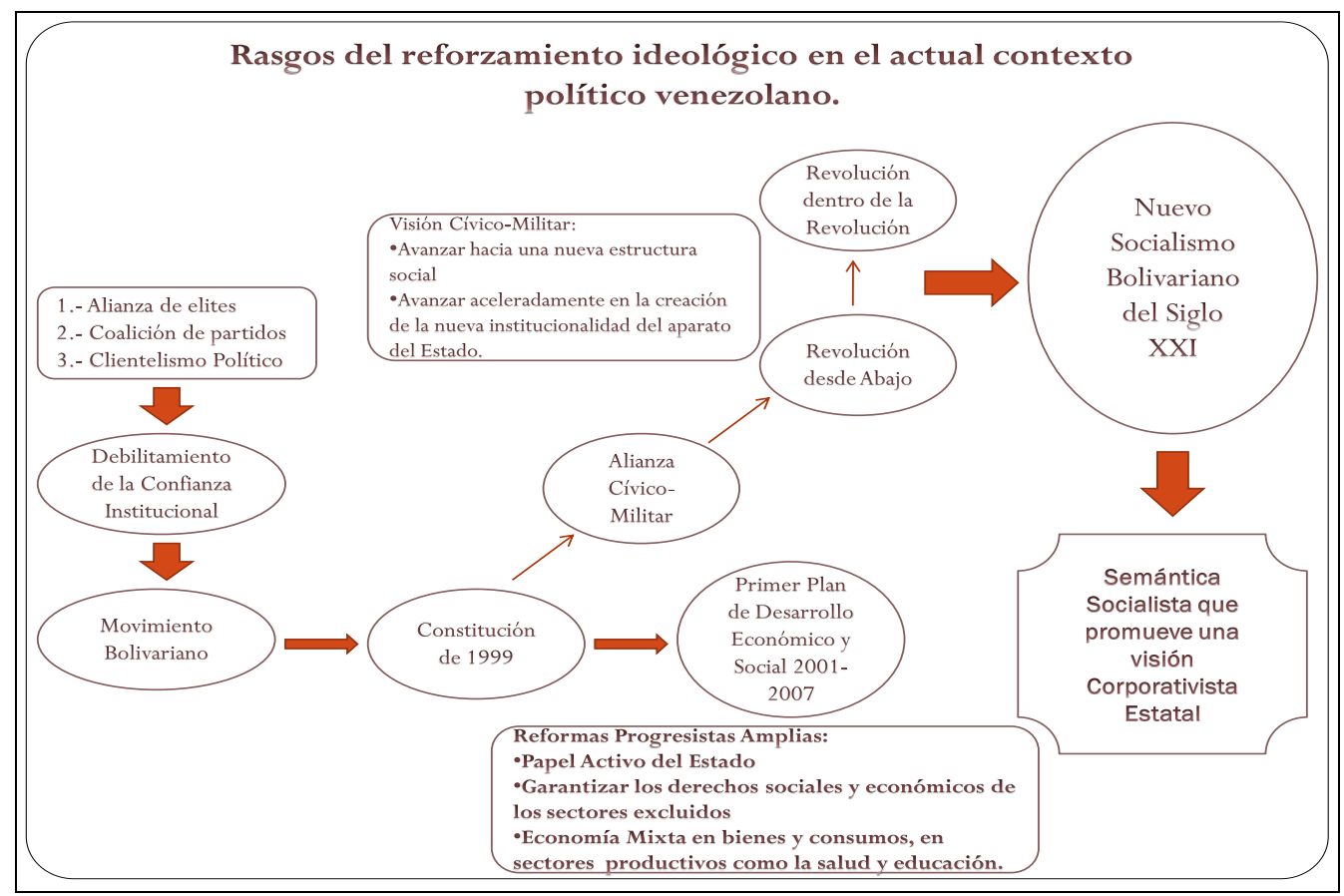

Fig. 2. Rasgos del reforzamiento ideológico en el actual contexto político venezolano

\section{La Confianza institucional en el contexto venezolano}

En la investigación hemos mencionado que las selecciones del gobierno bolivariano poco a poco lo irán orientando hacia el Nuevo Socialismo Bolivariano del siglo XXI. Tal como lo hemos estado observando, existen varias etapas para la consolidación de este proyecto político (Constitución de 1999, Plan Bolívar 2000, Revolución desde abajo y Revolución desde adentro). Dos visiones especifican la manera de llevar a cabo sus intenciones: del año 1998 al año 2003 las decisiones tomadas por el gobierno bolivariano proponían fortalecer y recuperar a las instituciones que no habían sido capaces de canalizar las demandas de los sectores más vulnerables. El segundo periodo es del 2004 en adelante y se caracteriza por proponer un proyecto político más pretencioso; el Nuevo Socialismo Bolivariano del siglo XXI. Resulta ahora importante poder empezar a analizar el problema de la confianza institucional en el contexto venezolano.

\section{Imposibilidad de Confianza Institucional en las Reformas Amplias}

Comentamos que con la Constitución de 1999 las expectativas que existían sobre la posibilidad de mejorar las instituciones del Estado eran altas. Tal como lo vimos en la tercera parte de la investigación, el apoyo hacia la democracia y hacia el gobierno aumentó considerablemente en el año 2000. Sin embargo, en la medida en que el gobierno fue adoptando otras soluciones a los problemas que iban aconteciendo, para muchos las expectativas se fueron debilitando. El gobierno ya no buscaba fortalecer a las instituciones públicas sino más bien reemplazarlas.

Tal como lo visualizamos en la tercera parte de la investigación, los principales problemas que se presentaron para poder comprometerse y cooperar con los valores y los objetivos que presentaba la nueva constitución son los siguientes: 
1) Desacuerdo en la manera de llevar a cabo las acciones (visión cívico-militar vs reformas amplias).

2) Falta de acuerdo entre el sector privado y el gobierno.

3) Falta de recursos para poder llevar a cabo lo consagrado en la Constitución.

La relación directa pueblo/gobierno y el apoyo de las fuerzas militares fue la solución a los obstáculos que se colocaban para agilizar o dinamizar los programas sociales a los sectores más necesitados. Pero también fue irritación para aquellos que tenían las expectativas de mejorar las instituciones públicas. El gobierno pudo rendir satisfactoriamente la prueba para poder consolidar su proyecto político y atribuir motivos para que los ciudadanos integren un programa de normas y valores revolucionarios. El gobierno pudo seleccionar nuevos presentes y ahora, se intenta construir una nueva institucionalidad para poder llegar al Nuevo Socialismo Bolivariano del Siglo XXI.

La confianza en las reformas amplias no logró generalizarse precisamente porque las acciones del gobierno no dirigían sus acciones hacia el fortalecimiento de las instituciones públicas ya existentes. Lo consagrado en la Constitución de 1999 y la implementación del Plan de Desarrollo Económico y Social 2001-2007 no lograron concretarse plenamente por los desacuerdos en la manera de llevar a cabo las acciones. Desde la economía, el sector privado hubiese tenido que aceptar el riesgo de validar el fomento de la economía social o la regularización de la propiedad de tierras. Desde la política los partidos políticos de la oposición hubiesen tenido que integrar un programa de valores distinta a la que ellas representan. O que los mismos integrantes del gobierno hubiesen tenido que aceptar implementar los planes de acción con la ayuda de las fuerzas militares

El problema de la confianza con el tiempo es que el futuro contiene muchas más posibilidades que el presente, por lo que el presente es considerado como el punto de partida que avanza continuamente hacia el futuro (Luhmann 1996). Cuando emergen decepciones, surge incertidumbre por parte de aquellos que están construyendo la confianza. Se sabe que el futuro contiene más posibilidades y existe el riesgo de que las acciones que se han realizado desde la toma del poder en 1998 sean rechazados para las futuras elecciones presidenciales. Es más fácil construir desconfianza que la confianza (Luhmann 1996) ya que si los resultados no son efectivos en un presente, se disminuyen las posibilidades de estabilizar el programa político propuesto por gobierno bolivariano. En esta incertidumbre el gobierno tiene que tomar decisiones para que el futuro que se quiere se haga realidad.

\section{EI Nuevo Socialismo Bolivariano y la disponibilidad de confianza:}

Hemos comentado en nuestro marco teórico que con la ideología, se tiene la esperanza que el presente del futuro sirva como lugar determinado para el cumplimiento de la promesa (Luhmann 2007). La posibilidad de construir el Nuevo Socialismo Bolivariano del Siglo XXI, como selección del gobierno para el año 2004 emerge porque el mismo proceso que se ha venido dando desde que se adopta la visión cívico militar "ha rendido satisfactoriamente la prueba" (Luhmann 1996). De esta manera, los valores han logrado estabilizarse para la selección de nuevos presentes y la población que acepta las intenciones del gobierno ha tenido la esperanza de que el futuro (el Nuevo Socialismo del Siglo XXI) sirva como un lugar determinado. Tal como lo analizamos en la tercera parte, se acepta un proyecto que promueve una visión corporativista estatal ya que el Estado ha tenido la capacidad de tomar las decisiones desde arriba para 
distribuir recursos y resolver los problemas de los sectores más vulnerables a partir de una nueva estructura administrativa, de un solo partido.

El tratamiento de los problemas básicos como la salud, la vivienda, la educación o la seguridad alimentaria le ha permitido generalizar las expectativas de los sectores más necesitados. Ha tenido la capacidad de tomar decisiones y de transformar las condiciones inestables (problema) en estables (solución) a partir de sus recursos disponibles (Luhmann 1996), a través de una relación directa entre el presidente y el pueblo.

Por lo tanto, el gobierno bolivariano ha logrado adquirir una disponibilidad de confianza, es decir, "recursos internos disponibles que en caso de una desilusión de la confianza pueden ponerse en acción y asumir la carga de reducción de complejidad y la solución de problemas"(Luhmann 1996; 139). Esto se puede ver reflejado en las distintas decisiones que el gobierno bolivariano ha tomado para mantener sus operaciones y consolidar su proyecto político desde una visión cívico-militar (MBR-200, Constitución de 1999, La Revolución desde Abajo, La Revolución dentro de la Revolución). Cada decisión ha solucionado una situación específica de riesgo y le ha permitido crear las condiciones para seguir seleccionado nuevas posibilidades de selección como ahora es el caso del Nuevo Socialismo Bolivariano del Siglo XXI. Ha logrado que el riesgo se mantenga bajo control (Luhmann 1996; 155) para una comunidad específica a través de una visión corporativista como la que describimos anteriormente.

Para poder observar la posibilidad de construir confianza desde esta visión rumbo al Nuevo Socialismo Bolivariano del Siglo XXI, necesitamos analizar los mecanismos que emplea o sus recursos disponibles que tiene el Estado para que sus acciones sean socialmente comprendidas y aceptadas. En este sentido, analizaremos los principales mecanismos utilizados por el gobierno para intentar construir confianza institucional.

\section{Misiones Sociales y Consejos Comunales como recursos disponibles para construir confianza institucional.}

En el Nuevo Socialismo Bolivariano, el Estado tiene que avanzar hacia una institucionalidad en la que el poder popular (Consejos Comunales, Misiones Sociales), el poder armado (La Fuerzas Armadas) y poder político (Partido Socialista Unido de Venezuela y el Estado) sean uno solo, bajo la disciplina de los valores revolucionarios (Cabezas 2007). De esta manera, implicaría que el Estado represente a los intereses bajo un arreglo institucional típico-ideal para vincular los intereses organizados en asociaciones de la sociedad civil con las estructuras decisionales del Estado (Schmitter en Medina 2003). En otras palabras, los recursos disponibles para construir confianza institucional desde un programa corporativista estatista estaría en que el Estado tenga la capacidad de subordinar a las organizaciones de la sociedad civil desde una institucionalidad específica. En el caso venezolano esta subordinación la observaremos a través de la estructura administrativa que tienen las Misiones Sociales y los Consejos Comunales.

La posibilidad de construir confianza institucional desde el Nuevo Socialismo Bolivariano la encontraríamos en un principio en las Misiones Sociales. Estas cumplirán un papel importante en el intento por institucionalizar los planes de acciones que se fueron ejecutando en años anteriores para atender las necesidades básicas de los sectores populares primordialmente en el área de la salud, la educación, la vivienda, el trabajo y la alimentación. Con la decisión de crear estas misiones, el gobierno 
bolivariano asegurará la continuidad del proceso para la consolidación del proyecto bolivariano.

El gobierno sabe que cuenta con un apoyo en los sectores populares, sabe que los planes de acción ejecutados en fechas anteriores han traído efectos positivos hacia los sectores más vulnerables y por lo tanto, sabe que existe un compromiso y una cooperación entre el gobierno y el pueblo. En ambas partes la confianza ha solucionado una situación específica de riesgo; por un lado el gobierno ha logrado que sus selecciones sean aceptadas y por otro, para muchos se han estabilizado las expectativas. Hay confianza, hay apoyo y por lo tanto, emerge la posibilidad de que los valores que definen al gobierno bolivariano bajo la visión cívico-militar sean integrados en los hábitos y en las prácticas sociales para futuros presentes.

Los recursos disponibles del gobierno bolivariano se observan en la creación de una nueva estructura administrativa para poner en marcha a las Misiones Sociales. Esta estructura administrativa se caracteriza porque el Presidente de la República tenga la capacidad de crear las misiones sociales, de decretar planes presupuestarios extraordinarios provenientes principalmente de los recursos petroleros y de designar las Comisiones Presidenciales para cada misión (Cabezas 2007). La nueva estructura administrativa permite dinamizar los programas sociales que, si hubiese pasado por el orden institucional tradicional hubiese implicado tiempo para llegar a acuerdos y ejecutar tales acciones, tiempo para que las experiencias se generalicen y se estabilicen en un futuro que siempre puede ser de otra manera.

Las Comisiones Presidenciales normalmente están integradas por los Ministerios y Organismos Públicos, las Fuerzas Armadas, Petróleos de Venezuela (PDVSA), miembros de las Organizaciones Sociales de la Revolución y en algunos casos personal cubano (Misión Barrio Adentro). Estos tienen que coordinarse con el Presidente de la República para poner en marcha a las misiones a partir de los recursos provenientes principalmente del petróleo.

El Presidente de la República es quien tiene la última palabra ya que éste crea, decreta y designa, por lo que estas Comisiones tienen que mostrarse así mismos confiables y por lo tanto, tienen que esforzarse para exhibir una diligencia, rectitud y prontitud para llevar a cabo las tareas lealmente (Luhmann 1996). De esta manera, se garantiza una efectiva coordinación entre las Comisiones y el Presidente.

La función principal de esta estructura administrativa será de estimular a los sujetos individuales a aceptar esta oferta comunicativa (integrarse a las misiones sociales) para que se siga estabilizando el nuevo tipo de socialización desde la visión cívicomilitar. Se tiene como propósito generalizar la confianza de la comunidad que acepta las intenciones del gobierno para que éste último pueda seguir operando y para que ambas partes solucionen una situación específica de riesgo.

Las acciones realizadas por las Misiones Sociales permite que los participantes conozcan la situación exacta y sepan que otros también la conocen por lo que se lograría estabilizar la indiferencia ante la variación en la medida en que rinden satisfactoriamente la prueba (Luhmann 1996). En otras palabras, en la medida en que la estructura administrativa se compromete en procesar los problemas (pobreza, educación, salud, vivienda, seguridad alimentaria), en la medida en que las Misiones Sociales son capaces de regular la incertidumbre o los riesgos sociales y en la medida en que traen resultados efectivos para los sujetos individuales que han aceptado el riesgo de confiar en el proyecto político del gobierno, existe la posibilidad de que la 
persona que co-experimenta lo mismo que el otro se sienta segura. Es decir, se crean las condiciones de posibilidad de que se generalicen las expectativas y que se estabilicen con respecto a un entorno inseguro, inestable y complejo.

Hemos enfatizado que la intención que tiene el gobierno bolivariano con las Misiones Sociales es de poder institucionalizarlas para poder crear un nuevo orden social revolucionario (Cabezas 2009). Ha logrado cumplir con una solución de problemas generalizados en una comunidad que acepta las intenciones del gobierno. Con esta capacidad, emerge la posibilidad de que los individuos se motiven a integrar un programa de normas y valores en sus prácticas sociales. Sin embargo, para poder integrarlas se requiere de un proceso de aprendizaje.

El proceso de aprendizaje está mediado por las experiencias del que aprende consigo mismo y es controlado por la identidad del desarrollo propio del que aprende (Luhmann 1996; Vanderstraeten 2000). En este sentido, las Misiones Sociales no controlan al sistema psíquico, no controlan su aprendizaje pero sí los estimulan a formar parte de esta nueva socialización en la medida en que éstas traen resultados efectivos. Emerge la posibilidad de aceptar los valores revolucionarios e integrarlas en la identidad propia del que aprende.

En la relación gobierno/pueblo, al integrar estos valores revolucionarios en sus prácticas sociales a través de un proceso de auto-aprendizaje, emerge un tipo de identificación emocional (Luhmann 1996) hacia la persona que dirige a estas Misiones Sociales. Es decir, emerge un tipo de familiaridad íntima con el objeto que regula y asegura la formación de expectativas (Luhmann 1996). En la medida en que el Presidente de la República - como la persona que decreta planes presupuestarios, designa a las Comisiones y crea las Misiones Sociales- generaliza las expectativas regulando la incertidumbre y las decepciones que emergen en un entorno complejo e inestable, los sujetos individuales se verán motivados a integrar los valores revolucionarios en sus prácticas sociales porque saben que otros también conocen la situación específica de riesgo y porque en ésta se han generalizado las experiencias.

La generalización de expectativa a través de un proceso de aprendizaje que integra estos valores revolucionarios a partir de una identidad emocional implica que lo externo sea negado como posibilidad (Luhmann 1996). Es decir, se excluyen todos los demás objetos o los relegan a una posición de relativa insignificancia, aún si en aspectos particulares producen resultados iguales o mejores (Luhmann 1996; 141). Esta "refutación externa" (Luhmann 1996; 138) se debe a la misma seguridad que existe en la situación específica de riesgo que es co-experimentada.

La relación entre el pueblo y el presidente reduce complejidad ya que éste último tiene la capacidad de generalizar las expectativas. Por lo tanto, se reducen las posibilidades del entorno, estableciendo la preferencia en un objeto, y en consecuencia al mismo tiempo establecen posibilidades internas de procesar la experiencia (Luhmann 1996). Las misiones sociales son un mecanismo para procesar las experiencias a través de la participación, y el pueblo se identifica con el presidente quien tiene la capacidad de regular y asegurar la formación de expectativas de una comunidad específica.

De esta manera, resulta posible que las misiones sociales logren generalizar la confianza de una comunidad que ha aceptado las intenciones del gobierno, y esta aceptación le permite al gobierno bolivariano tener la posibilidad de seleccionar nuevos presentes para seguir consolidando su proyecto político bolivariano como lo es ahora el Nuevo Socialismo Bolivariano del Siglo XXI. 
Otro recurso que dispone el gobierno bolivariano son los Consejos Comunales. Tal como lo señalamos en la segunda parte de la investigación, "Ios Consejos Comunales como forma específica de organización para la participación ciudadana, no aparecen mencionados en la Constitución de 1999, ellos son una creación de la legislación ordinaria" (Romero 2007; 125). En este sentido, con sus recursos internos disponibles, para el año 2006, el gobierno bolivariano decidió crear esta nueva forma de organización como posible solución al problema de la nueva estructura social que el gobierno bolivariano quiere alcanzar. Como menciona Hugo Chávez (2007), éstas serán parte integral de la nueva estructura del poder comunal.

Al igual que en las Misiones Sociales el presidente designa una Comisión para la coordinación de los Consejos Comunales. Esta está integrada por el Vice-presidente de la República y el ministro del Poder Popular para la Participación Popular y Desarrollo Social (MINIPADES) como secretario ejecutivo (Romero 2007). La Comisión tiene que mostrarse confiable y ser leal a las decisiones del Presidente. Por lo tanto, a través de esta transmisión de las selecciones del Presidente, las Comisiones tienen generar una comunicación efectiva con el pueblo para que éstas puedan organizarse conforme a lo que propone el Presidente de la República. Las Comisiones deben tener la capacidad de mantener los riesgos bajo control para que la participación sea efectiva y se mantengan estables las expectativas.

Los Consejos Comunales al igual que las Misiones Sociales son un mecanismo para procesar las experiencias a través de la participación (Luhmann 1996). Cada integrante cumple una función específica en sus respectivas comunidades y el Presidente, a través de su Comisión es quien logra distribuir los recursos necesarios primordialmente desde los recursos provenientes del petróleo - para que las comunidades se organicen y cumplan con el programa establecido. A diferencia del Estado Social de Derecho que promueve la autonomía de las organizaciones, éstas quedan subordinadas a las decisiones del Presidente de la República. Como sostiene Rafael Romero, la comunidad participa como apoyo administrativo para la solución del problema que se trate, pero el poder de la decisión al respecto se mantiene en los órganos formales del gobierno (Romero 2007). Tal como lo acabamos de mencionar, el programa de carácter corporativista estatal implica que las asociaciones o las organizaciones queden controladas por el aparato Estatal. En este sentido, los participantes tienen que cumplir con su deber para poder llegar a ese lugar determinado que propone el Nuevo Socialismo Bolivariano del Siglo XXI. Cada sujeto individual es personalmente responsable de sus acciones pero éstas están atribuidas no únicamente a la personalidad, sino también al presidente de la República a través de la Comisión Presidencial, a través de los Consejos Comunales.

En esta relación directa, cada uno de los participantes establece su preferencia por el objeto que regula y asegura la formación de expectativas (el Presidente de la República) ya que él es quien distribuye los recursos para que se organicen las comunidades y puedan participar en las decisiones públicas. Es quien reproduce un discurso que motiva un input de energía para situaciones que son hasta ahora indeterminadas (Luhmann 1996). En estos Consejos Comunales, al igual que en las Misiones Sociales, se establece una relación de poder que resulta interesante visualizar.

El medio del poder desde la perspectiva sistémica, se caracteriza porque "la acción de alter está involucrada en determinar cómo ego selecciona sus acciones" (Luhmann 1995; 31). En otras palabras, en el caso concreto de la nueva estructura 
administrativa, la acción del Presidente de la República - a través de su Comisión- está involucrada en determinar cómo los participantes de los Consejos Comunales seleccionan sus acciones. Implica por lo tanto que las acciones de los Consejos Comunales están atribuidas al Presidente de la República ya que éste último motiva a los participantes a que sus intenciones sean realizadas a través de sus recursos disponibles.

De igual manera, comentamos que el poder descansa sobre el hecho de que existen posibilidades cuya realización es evitada. Es decir, para que la acción de ego esté involucrada en determinar cómo alter selecciona sus acciones, se tienen posibilidades de alternativas como es el caso de la amenaza.

Para analizar la relación de poder que existe entre el gobierno y el pueblo tomemos como ejemplo un estudio realizado por Yolanda D'Elia. En una entrevista realizada por esta autora hacia los integrantes de las organizaciones del gobierno bolivariano, se determinó que:

"el malestar con las misiones sociales, los consejos comunales y con los actores políticos no traspasa los límites de la comunidad, porque en forma oculta o abierta la crítica a la gestión se entiende como disidencia con el proceso y ésta puede llegar a ser castigada con obstrucciones al servicio [...] cuando la desconfianza es disipada, la principal solicitud de las organizaciones es que el presidente se entere de lo que está ocurriendo" (D'Elia 2006; 218).

Por lo tanto, en el caso de los Consejos Comunales o en la Misiones Sociales, los participantes deben mostrarse confiables en sus tareas que tienen que cumplir ya que si se detecta una desconfianza hacia las intenciones que se realiza en la comunidad, los integrantes corren el riesgo de ser sancionados.

Tanto en las Misiones Sociales como en los Consejos Comunales, la esperanza (el Nuevo Socialismo del Siglo XXI) se encuentra en la cooperación y en el compromiso. El gobierno ha logrado que el proyecto bolivariano sea para una comunidad específica un hecho inevitable de la vida (familiaridad) no sólo porque el otro co-experimenta lo mismo que yo, sino también porque las selecciones del gobierno ha tenido una capacidad de solución de problemas generalizadora a partir de sus recursos disponibles. Emerge un proceso de socialización que gira en torno a un programa de normas y valores que representan al proyecto bolivariano. Existe un tipo de familiaridad íntima con el objeto que regula y asegura la formación de expectativas (Luhmann 1996), es decir, con el presidente de la República quien tiene la capacidad de decidir; esto y no lo otro. Por lo tanto, reduce las posibilidades del entorno estableciendo la preferencia en un objeto (Luhmann 1996). 


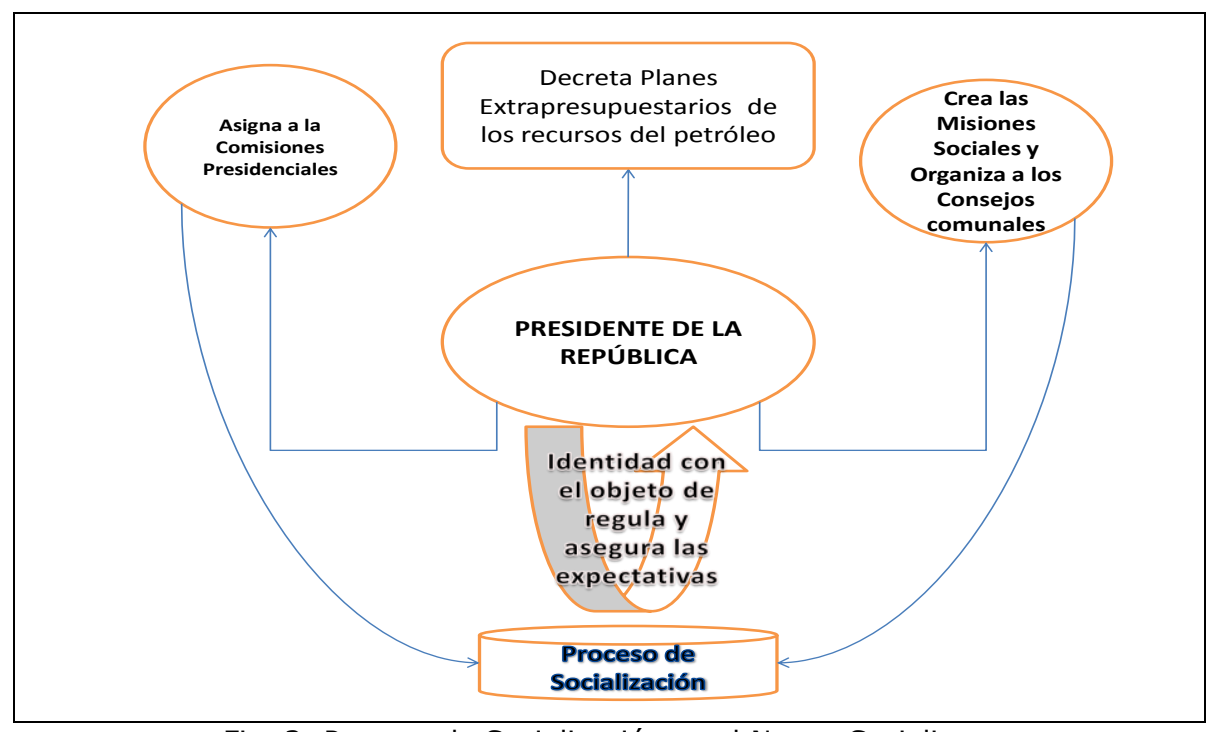

Fig. 3: Proceso de Socialización en el Nuevo Socialismo

La expectativa está asegurada de la refutación externa (Luhmann 1996) es decir, el Nuevo Socialismo del siglo XXI como un lugar determinado, refuerza la unidad de los que apoyan este proyecto ya que existe un compromiso que se debe asumir para lograr el objetivo de llegar al Nuevo Socialismo y por lo tanto, lo externo (lo no familiar) es visto como una amenaza que atenta con el cumplimiento de la promesa y llegar a ese presente del futuro.

A pesar de que la identidad hacia un objeto es el principal mecanismo para reducir complejidad en un entorno complejo e inestable, podemos detectar un problema con esta relación gobierno/pueblo. "La familiaridad cercana impide que el problema de la confianza se convierta en materia de reflexión y cuando la reflexión realmente ocurre su primera víctima es precisamente la familiaridad" (Luhmann 1996). Con este reforzamiento ideológico el Estado, a través de sus recursos disponibles, es capaz de limitar la capacidad reflexiva de los sujetos individuales precisamente porque se establece la preferencia hacia un objeto que tiene la capacidad de regular y asegurar las expectativas de una comunidad específica. Sin embargo, cuando la reflexión se hace visible, el Estado tiene que emplear alternativas evitables ya que si se generalizan estas decepciones el gobierno corre con el riesgo de no poder seleccionar nuevos presentes. Las alternativas evitables precisamente son el principal recurso que tiene el presidente de la república para mantenerse en el poder y la amenaza está justamente en la posibilidad de limitar recursos -que provienen de la renta petrolera!que los sectores vulnerables necesitan para solucionar sus problemas específicos de riesgos (salud, educación, alimentación, vivienda, etc).

En este sentido, el Nuevo Socialismo Bolivariano del Siglo XXI produce confianza por medio de un enfoque corporativista estatal precisamente porque su estructura administrativa tiene la capacidad de controlar o subordinar a las organizaciones de una comunidad específica a través de la distribución de recursos provenientes principalmente de los recursos del petróleo para resolver los problemas sociales y económicos de los sectores vulnerables. Existe una relación directa entre el pueblo y el presidente ya que éste último es capaz de regular y asegurar las expectativas de los sujetos que apoyan las intenciones del gobierno. Esta familiaridad íntima reduce las condiciones de posibilidad de que se use la capacidad reflexiva de los actores para poder atribuir sus decisiones otros sistemas que estén más allá de la comunidad a la 
cual se integran. La confianza queda reducida a un objeto; al presidente de la república.

\section{Imposibilidad de Confianza Institucional en el Nuevo Socialismo Bolivariano del Siglo XXI:}

Sostenemos que "la acción instrumental orientada a efectos lejanos, puede institucionalizarse si el horizonte temporal de un sistema está extendido adecuadamente por medio de la confianza" (Luhmann 1996; 154). El gobierno ha tenido la capacidad de seleccionar nuevos presentes para hacer penetrar las Misiones Sociales y los Consejos Comunales en el tejido social pero no ha tenido -por ahora- la capacidad de institucionalizarlas justamente porque éstas no han logrado extender suficiente confianza hacia los ciudadanos en el contexto venezolano. Hemos visto que hubo un intento con la llegada de la Constitución de 1999; había suficiente confianza y se empezaron a definir las normas y valores para la selección de nuevos presentes, sin embargo, las expectativas se fueron debilitando precisamente por los desacuerdos entre las distintas comunicaciones especializadas con el gobierno bolivariano. Como solución a este problema el gobierno dirigirá sus acciones hacia el nuevo socialismo del siglo XXI.

La imposibilidad de construir confianza institucional en el Nuevo Socialismo Bolivariano del Siglo XXI está justamente en que el horizonte temporal del Estado, bajo la visión cívico-militar no ha logrado extender suficientemente la confianza para avanzar hacia una nueva institucionalidad en la que el poder popular (Poder Comunal, Misiones Sociales), el poder armado (Milicias Bolivarianas y La Fuerzas Armadas) y poder político (Partido Socialista Unido de Venezuela y el Estado) sea uno solo, bajo la disciplina de los valores revolucionarios.

Aceptar esta acción socialmente comprensible implicaría que las instituciones públicas tradicionales sean remplazadas por las Misiones Sociales y los Consejos Comunales. Implicaría que éstas logren penetrar en todo el tejido social y que tengan la capacidad generalizar la confianza y mantenerse temporalmente para futuros presentes. Las Misiones Sociales o los Consejos Comunales, a través de sus respectivas Comisiones y el Presidente de la República, tendrían que tener la capacidad de mantener las expectativas públicas, el riesgo bajo control y hacer que la cuota de desilusiones no sea demasiado grande(Luhmann 1996), no únicamente en una comunidad específica, sino también en todo el contexto venezolano.

La imposibilidad de construir confianza institucional en el contexto venezolano se debe justamente a que se reducen las condiciones de posibilidad de "armonizar con un entorno más complejo" (Luhmann 1996; 144). Hemos estado comentando que la confianza que ofrece el gobierno queda reducida a una comunidad específica que acepta las intenciones del gobierno precisamente porque se reduce complejidad reforzando la unidad a partir de una identidad con el objeto que regula y asegura las expectativas; el Presidente de la República.

Sin embargo, si colocamos a la sociedad venezolana en el contexto de una sociedad moderna, para muchos las decisiones riesgosas no dependen de la atribución a un proceso político o a un presidente como el único que tiene la capacidad de asegurar las expectativas sino más bien de las distintas comunicaciones especializadas que también son equivalentemente funcionales para resolver los problemas sociales sin estar determinados por las decisiones de un líder. 
Por lo tanto, la identidad del yo presentado o la auto-presentación significa que los individuos tengan la capacidad de cambiar las situaciones de su presentación y sus atributos y hacerse independiente del destino de los objeto específicos del entorno (Luhmann 1996). Significa tener la capacidad de realizar cálculos internos de las condiciones externas que generan riesgos para atribuir una acción y tener la libertad de negar otras posibilidades. Para extender a la confianza más allá de una comunidad específica se requiere de una "libertad institucionalizada, es decir, la libertad coartada y moderada por el orden social; la libertad como un complejo de acciones o aspecto de acciones por los cuales uno es personalmente responsable" (Luhmann 1996; 69). En el contexto venezolano, la propuesta de confianza del gobierno bolivariano con el Nuevo Socialismo del siglo XXI -por ahora- limitaría la capacidad de hacerse independiente de los objetos específicos del entorno. En otras palabras, se reduce la capacidad no sólo de atribuir acciones a las distintas comunicaciones especializadas, sino también de negarlas y optar por otras soluciones funcionalmente equivalente.

Vale tener claro que no se pone en duda que la gente que apoya las intenciones del gobierno tenga esta capacidad reflexiva. Es más, el hecho de aceptar el riesgo de comprometerse con el proyecto bolivariano y negar otras posibilidades depende de su capacidad para realizar un cálculo interno de los riesgos externos. El hecho de evitar sanciones por el gobierno que observa desconfianza en una comunidad también requiere de una capacidad reflexiva. Sin embargo, se observa que en el proceso que se ha estado llevando a cabo para muchos la identidad en un objeto tiene más relevancia que la identidad del yo presentado ya que para ellos es la manera más efectiva de reducir complejidad, es un equivalente funcional a las distintas formas organizadas que también reducen complejidad y que en los años 90 no tuvieron la capacidad de generalizar las expectativas.

Sin embargo, la imposibilidad de construir confianza institucional -por ahora- la encontramos en que las expectativas se mantienen únicamente en esta comunidad específica. Las expectativas no logran generalizarse más allá de esta comunidad precisamente porque los distintos actores estratégicos observan que el hecho de identificarse con un objeto, limita la capacidad de tomar decisiones en un entorno más complejo y de tener la disposición de sustituir racionalmente estrategias a través de la capacidad reflexiva que vamos adquiriendo en el proceso de aprendizaje para tolerar las diferentes formas de considerar el mundo (Luhmann 1996).

Hemos comentado en nuestro marco teórico que la experiencia es un prerrequisito fundamental para poder enfrentar la complejidad del mundo en que vivimos y por lo tanto ésta es llevada al sentido organizado y al mundo con el objeto de hacer comprensibles las condiciones complejas de nuestra existencia (Luhmann 1996). Es lo que permite orientarnos en nuestras decisiones que tomamos a cada instante en un mundo que es experimentable en todas partes, en cada situación y que puede moverse desde cualquier punto hacia otro (Luhmann 1998).

El proyecto bolivariano ha logrado hacer comprensible para una comunidad específica la complejidad del mundo en que vivimos bajo una representación de ideas y de valores de carácter revolucionario. En la medida en que el gobierno bolivariano ha solucionado una situación específica de riesgo, ha tenido la posibilidad de seleccionar nuevos presentes para que los sujetos individuales que aceptan las intenciones del gobierno, co-experimenten lo mismo y comprendan un mundo complejo a partir de temas que se caracterizan por representar un sistema de normas y valores revolucionarios. 
Esto implica por lo tanto que los sujetos individuales que aceptan esta integración de normas y valores, experimenten un mundo determinado por un objeto que regula y asegura la formación de expectativas (Luhmann 1996). Hemos mencionado que las Misiones Sociales o los Consejos Comunales son uno de los principales mecanismos que usa el gobierno para generalizar las expectativas y éstos son coordinados por el presidente a través de sus comisiones para que todos lleven a cabo las tareas lealmente.

Si colocamos a la sociedad venezolana en el contexto de una sociedad moderna, más allá de la familiaridad íntima entre el pueblo y el gobierno es el riesgo lo que se vuelve familiar. El gobierno ha logrado solucionar una situación específica de riesgo que, por rendir satisfactoriamente la prueba, ha podido estabilizar los valores y las normas que han sido aceptados por una comunidad específica para integrarlas en sus prácticas sociales. Para muchos ésta sería una solución a un problema de la inestabilidad de su entorno complejo.

Sin embargo, la accesibilidad del mundo no se reduce a una relación íntima entre el pueblo y el gobierno, ésta última es una forma, una posibilidad, que emerge en un contexto en la que ni las políticas neoliberales, ni las instituciones del estado tradicional fueron capaces de mantener la estabilidad social en los 90. Una forma equivalentemente funcional que logra solucionar un problema específico de riesgo. Sin embargo, en el mundo que se nos hace socialmente comprensible existen otras formas para poder "encajar en el mundo" (Glasserfeld 1997) para reducir complejidad. Las experiencias son diversas y por lo tanto, se requiere precisamente diversificar la confianza para que uno tenga la posibilidad de aceptar el riesgo, para que el futuro se haga presente sabiendo que -si el éxito no llega- se tiene la posibilidad de seleccionar otras posibilidades.

En el contexto venezolano, la atribución de motivos por parte del gobierno bolivariano no es aceptada por muchos ya que sus decisiones riesgosas no necesitan estar determinadas por una relación íntima entre el gobierno y el pueblo. En el mundo, complejo existen distintos temas de comunicación que reproducen las instituciones como forma o como sentido organizado- en sus distintas especialidades que permite que el mundo se nos haga socialmente comprensible. Por lo tanto, existen distintas racionalidades que también regulan y aseguran la formación de expectativas y que son equivalentemente funcionales a aquellas que ofrece el gobierno bolivariano.

Permiten que podamos acceder a este mundo en cada instante, en un mundo que es experimentable en todas partes, en cada situación y que puede moverse desde cualquier punto hacia otro (Luhmann 1998) para tomar decisiones y soluciones situaciones específicas de riesgos sin estar determinada a la relación familiar gobierno/pueblo, sin estar determinado por un único objeto que regula y asegura la formación de expectativas.

Tal como lo vimos en la segunda parte de la investigación existe irritación hacia la oferta de confianza del gobierno bolivariano precisamente porque para muchos resulta ser una inversión riesgosa en sus futuras decisiones. Cambiar la propiedad privada por la propiedad social, eliminar la autonomía de las universidades públicas, eliminar las entidades regionales y municipales por un poder comunal, eliminar la autonomía del Banco Central, remplazar una democracia participativa por una democracia socialista, remplazar la autonomía de las fuerzas armadas y unirla a la sociedad civil, etc. Son selecciones que causan temor ya que en un mundo que se nos hace familiar existe el riesgo de que el futuro del presente haya decepción precisamente porque el mundo 
que se les hace socialmente comprensible necesitan de otras formas sociales o racionalidades (el mercado por ejemplo) que también reducen complejidad y absorben la incertidumbre.

\section{Conclusiones}

Nuestra investigación buscaba identificar en un principio los rasgos del reforzamiento ideológico en el actual contexto político venezolano. Sostenemos que los elementos que se presentarán en el reforzamiento ideológico, como un primer piso para la constitución del Socialismo Bolivariano provienen del MBR-200. Se retoma distintos personajes históricos para orientar el "proyecto propio" de transformación que se imagina para el país. Se propone un proyecto de transformación para el país, una institucionalidad diferente a aquellas propuestas presentadas por las políticas neoliberales y por los gobiernos tradicionales que fueron incapaces de mantener la expectativa pública y el orden social y político.

De esta propuesta, emergen para el año 1998 dos visiones que se confrontarán en la manera de dirigir el Nuevo Estado Social de Derecho. Parten de interpretaciones diferentes acerca de la realidad venezolana y postulan distintas formas de organización del Estado para superar los problemas que en ellos se observan" (D’Elia 2009):

1) La visión de las reformas Amplias (1999-2003) buscaba fortalecer y recuperar a las instituciones públicas a través de un papel activo del Estado que garantizara los derechos sociales y económicos de los sectores más excluidos. De igual manera, se planteaba una especie de economía mixta en bienes y consumos y en sectores productivos como la salud o la educación para hacer efectiva la universalización de los derechos y una justa distribución de la riqueza. El rescate de lo público era el espacio para el ejercicio de una verdadera democracia que debía sustentarse en la participación protagónica de todos en función del interés de todos (D'Elia 2008). Los Documentos que caracterizan a esta visión: Agenda Alternativa Bolivariana, Movimiento V República, Constitución de 1999, Plan de Desarrollo Social y Económico 2001-2007.

2) La visión cívico-militar toma acciones directamente con el pueblo para dinamizar los programas sociales, con el apoyo de las fuerzas militares. En este sentido, se empieza a observar que las acciones tomadas por el presidente de la república del gobierno bolivariano, irá tomando otro camino con respecto a lo planteado en los documentos presentados antes de esta fecha. Ya no se está planteando el fortalecimiento y la recuperación de las instituciones tradicionales, sino más bien reemplazarlas. La institucionalidad del Estado ya no avanza hacia poderes públicos abiertos. Más bien, avanza hacia la fusión entre el poder popular, poder armado y poder político en uno solo, bajo la disciplina de los valores revolucionarios (Cabezas 2007). Documentos que caracterizan esta visión: Plan Bolívar 2000, Nuevo Mapa Estratégico, Plan de Desarrollo Social y Económico 2007-2013, 5 Motores Constituyentes, Reforma Constitucional.

El estudio también buscaba analizar la posibilidad que existe para construir confianza institucional en el Nuevo Socialismo Bolivariano del Siglo XXI. Encontramos que esta posibilidad se encuentra en la disponibilidad de recursos que ha podido ir adquiriendo el gobierno bolivariano en la medida en que ha rendido satisfactoriamente la prueba. En ellas encontramos a las Misiones Sociales y a los Consejos Comunales como los principales recursos disponibles que tiene el gobierno para procesar las experiencias a través de la participación y tener la posibilidad de construir un nuevo orden social 
revolucionario a través de un nuevo proceso de socialización, una familiaridad íntima entre el gobierno y el pueblo.

De igual manera intentamos, responder nuestra hipótesis general que tiene con que el reforzamiento ideológico dificulta la posibilidad de construir confianza institucional. Encontramos que el Nuevo Socialismo Bolivariano es incapaz de producir confianza institucional precisamente porque no logra extender la confianza más allá de esta relación íntima entre el pueblo y el gobierno. La confianza queda generalizada únicamente en una comunidad específica y no logra ir más allá debido a que esta relación gobierno/pueblo limita la posibilidad de poder actuar en un entorno más complejo. Se debilitan las expectativas de los sujetos individuales hacia un proyecto político que limita la posibilidad de actuar más allá de una comunidad determinada políticamente.

Esta investigación permitió reflexionar sobre la evolución que ha tenido una política venezolana. La experiencia que han tenido los estados desarrollistas se pueden ver ahora reflejadas en un Estado que busca dirigirse hacia el Nuevo Socialismo Bolivariano del Siglo XXI a través de una relación íntima entre el pueblo y el gobierno. A través de la renta petrolera el gobierno ha tenido la capacidad de crear una nueva estructura administrativa paralela a las instituciones tradicionales con la finalidad de instalar en el contexto venezolano una nueva institucionalidad que avance hacia el Nuevo Socialismo Bolivariano. Una visión corporativista en la que las organizaciones quedarían subordinadas a las decisiones estructurales de un Estado que tiene la capacidad distribuir los recursos necesarios para resolver los problemas sociales de los sectores más vulnerables.

Se admite que el mundo que se hace socialmente comprensible en el contexto venezolano ha sido la relación directa petróleo/gobierno/pueblo desde que se instala la democracia en este país en 1958. Este tema ha logrado permanecer en la comunicación precisamente porque los partidos políticos han podido solucionar los problemas específicos de riesgo de la población venezolana. El gobierno bolivariano reutiliza este tema ya que con el petróleo ha logrado regular y asegurar las expectativas de los sectores vulnerables a través de la distribución de recursos. Sin embargo, para muchos es un riesgo ya que la experiencia dice (véase el debilitamiento de las instituciones tradicionales) que los estados desarrollistas no fueron capaces de mantener la expectativa pública a través de la renta petrolera.

Si colocamos a Venezuela en la sociedad moderna, el problema que existe con el gobierno bolivariano -y los partidos políticos tradicionales!- es precisamente el control o la centralización bajo la forma de dominio (corporativismo estatal, semicorporativismo) en una sociedad cada vez más diferenciada y compleja. Es decir, en la sociedad mundial, en donde "lo que se está observando es una red heterárquica de enlaces de comunicación en el plano de las organizaciones y las profesiones (Luhmann 2004; 238), el Estado Nacional venezolano sigue manteniendo una comunicación que se describe así mismo como el regulador y asegurador de las expectativas en un solo objeto; el Estado a través de un líder por medio de la distribución de recursos a través de la renta petrolera.

Aceptamos que en una sociedad que ha evolucionado y que se ha hecho cada vez más funcionalmente diferenciada, el Estado es sólo una forma del sistema político mundial. "El sistema político mundial, sobre la base de una diferenciación por funciones de la sociedad/mundo, es un sistema parcial que se distingue de otros sistemas parciales: economía, ciencia, derecho, medios de masas y a su vez diferenciados internamente 
bajo la forma de eso que nosotros llamamos estados territoriales" (Luhmann 2004; 238). En el contexto venezolano, el Nuevo Socialismo Bolivariano del siglo XXI trata de producir un nuevo orden social en el que el Estado sea el centro, una jerarquía en el que la comunicación política predomina sobre otras comunicaciones especializadas. Se admite por lo tanto, que la efectividad de las instituciones depende de que el Estado "proteja a la dinámica propia" (Luhmann 2004) de las instituciones que tienen por función hacerse cargo de las decepciones bajo sus propias lógicas ya que son ellas las que coordinan y las que conectan a las diferentes comunicaciones especializadas como la económica, política, jurídica, científica, educativa o la de salud, con las demandas de los ciudadanos. Por lo tanto, son los mediadores para garantizar la estabilidad y para generalizar la confianza de una sociedad diferenciada.

En lo que respecta a nuestro objeto de estudio, la relevancia de estudiar el problema de la confianza institucional y el reforzamiento ideológico está precisamente en que la confianza es un requisito previo para garantizar el orden social. En este sentido, sostenemos que "en las sociedades complejas, para generar sistemas, requieren de más confianza personal como prerrequisito de participación, y más confianza generalizada como una condición de mejores utilizaciones de oportunidades" (Luhmann, 2000: 97). Creemos que la relación íntima entre el pueblo y el gobierno bolivariano reduce las condiciones de posibilidad de que la población pueda diversificar su confianza para aprender a tolerar las diferentes formas de considerar el mundo y poder participar en ellas. Se limita la capacidad reflexiva de poder actuar en una sociedad compleja ya que el Estado asume la tarea de hacerse cargo de una población distribuyendo los recursos a través de la renta petrolera.

Desde las Ciencias Sociales, este estudio hizo el ejercicio de no aproximarse o anticiparse lógicamente a los resultados, más bien se hizo el ejercicio de dejar a la investigación la tarea de completar el proceso (Luhmann 1973). En otras palabras, el análisis de la confianza institucional desde la teoría de los sistemas sociales nos permitió ir identificando los problemas, como datos de donde partir (Luhmann 1973), en el contexto venezolano y observar sus soluciones como posibilidades. Utilizamos una metodología funcional para observar las selecciones contingentes que tienen los distintos actores para reducir complejidad. Por lo tanto, en las selecciones del gobierno o de la población venezolana, varias posibilidades de la realización aparecen equivalentes en el sentido funcional. Esta metodología es relevante para el estudio de los fenómenos sociales ya que el conocimiento no se construye a partir de una determinación apriorística de lo cultural (justicia, solidaridad), no se construye a partir de una determinación de valores presupuestos, sino más bien de las variaciones de las variables dentro de los sistemas complejos (Luhmann 1973). Esta perspectiva amplia las condiciones de posibilidad de abordar los cambios que se generan en los fenómenos que estamos estudiando desde la mirada de la complejidad, desde algo que puede ser y también no ser, de algo que es reemplazable (Luhmann 1973).

Para finalizar, este estudio que acabamos de realizar, sólo puede ser una aproximación a lo que está ocurriendo en el contexto venezolano. Creemos que se necesita profundizar más sobre el nuevo proceso de socialización que se está vivenciando en el contexto venezolano. Las misiones sociales o los Consejos Comunales son objetos de estudios que requiere de mayor profundidad y más desde la perspectiva de la teoría de los sistemas sociales. A pesar de que el gobierno ha logrado reforzar la unidad a partir de la identidad hacia un objeto, la capacidad reflexiva de los sujetos individuales no se ha eliminado. Acordémonos que las Misiones Sociales o los Consejos Comunales sólo estimulan a que se integren a este proceso de socialización. En este sentido, sería interesante abordar nuevos estudios que nos permitan analizar, el problema de la 
confianza personal de los sujetos individuales que integran este nuevo proceso de socialización ya que se tienen que enfrentar a una sociedad compleja.

Acordémonos que el gobierno bolivariano quiere construir un nuevo orden social revolucionario y por lo tanto, en una sociedad compleja, el presidente necesita conectarse con las comunicaciones especializadas. Por ejemplo, las Misiones Sociales no únicamente otorgan educación, salud y vivienda, sino que también producen formas para actuar en un entorno complejo; Misión Ciencia o las Universidades Bolivarianas, serían una de ellas y también requieren ser estudiadas. Por lo tanto, "el Estado Nacional no sólo está conectado con el sistema político del mundo, sino es al mismo tiempo una importante fuerza impulsora de dirección de la globalización de los otros sistemas funcionales (Luhmann en Nafarrate 2004; 241). En este sentido, por más que el Estado quiera ser en centro ordenador, por más que quiera politizar las distintas comunicaciones, el gobierno tiene que operar en el sistema/mundo y acoplarse con otros sistemas funcionales (derecho, economía, ciencia) para poder seleccionar nuevos presentes en una sociedad compleja.

Por último, esta investigación es un aporte a la producción de conocimiento sobre la confianza desde la perspectiva sistémica en América Latina. Son muy pocas, para no decir ninguna, las investigaciones que se han realizado sobre la confianza desde esta perspectiva. Las investigaciones encontradas sobre la confianza, además de ser pocas, se relacionan más que todo con el capital social (determinación de fines) o con la perspectiva de la sociedad civil, lo cual reduce las condiciones de posibilidad de verla desde la mirada de la complejidad. En América Latina las investigaciones sobre la confianza se podría observar también en los estudios que buscan modelar el problema de la confianza para predecir las expectativas que los individuos tienen sobre otras personas, instituciones, gobiernos o valores como la democracia, justicia, libertad e igualdad. Creemos que si aceptamos estos argumentos, resulta entonces insuficiente estudiar el problema de la confianza social bajo un paradigma que predice cómo debe de comportarse la sociedad, esto reduciría las condiciones de posibilidad de observar a una sociedad compleja y por lo tanto, observar al concepto de la confianza como una dimensión reflexiva y multidimensional que no depende de una certeza apriorística. $\mathbf{R M}$

\section{Bibliografía}

BARBER B. 1983. The logic and limits of trust. New Jersey: Editorial Rutgers University Press.

BERMÚDEZ E. 1998. La articulación de un sentido para la acción colectiva. En: Revista Espacio Abierto, 9 (1); 53-77.

BERIAIN J. 2008. Aceleración y tiranía del presente: la metamorfosis en las estructuras temporales de la modernidad. DF: Editorial Anthropos.

BLAU M.1982. Intercambio y poder en la vida social. Barcelona: Editorial Hora.

CABEZAS F. 2008. Las misiones sociales en Venezuela. Caracas: Editorial ILDIS.

CORSI G. ESPOSITO E. y BARALDI C. 2006. Glosario sobre la teoría social de Niklas Luhmann. DF: Editorial Universidad Iberoamericana. 
D’ELIA Y. y MAINGón T. 2009. La Política Social en el modelo Estado/Gobierno Venezolano. Caracas: Editorial IIdis.

EASTON D.1965. A System Analysis of Political Life. Chicago: Editorial University of Chicago Press.

FLEURY S. 1999. Reforma del Estado en América Latina ¿Hacia dónde? En: Revista Nueva Sociedad, 160, 58-80.

GIACALONE R. 2009. Transición política y constitución: una revisión de América Latina. En: Mariñez Freddy (ed.) Ciencia Política: nuevos contextos, nuevos desafíos. Bases del análisis político. DF: Noriega Editores, Segunda Edición.

GIDDENS A. 2002. La tercera vía: la renovación de la socialdemocracia. Madrid: Editorial Taurus.

GLASSERFELD E.1997. El final de una gran ilusión. En: Fischer H, Retzer A, Scheweizer J. (eds). El Final de los grandes proyectos. Barcelona: Editorial Gedisa.

GROSSKOPF A. 2002. Explaining the democratic trust conundrum. The sources of institutional trust in reunited Germany. En: International Social Science Review. 83 (1 \& 2), 1-25.

JAVALA J. 2003. From Norms to Trust: The Luhmanian Connections between Trust and System. En: Revista European Journal of Social Theory, 6(2), 173-190.

LANZ R. 2002. Dilemas de la construcción democrática. Una mirada desde Venezuela. En: Foro Interno: Anuario de Teoría Política, 2, 51-72.

LEVI M.1996. Social and Unsocial Capital: A review Essays of Robert Putmam's Making Democracy Work. En: Revista Politics \&Society, 24 (1). 45-55.

LÓPEZ MAYA M. 2004. Venezuela 2001-2004: actores y estrategias. En: Revista Cuadernos del Cendes, 56 (21), 105-128.

LÓPEZ MAYA M. 2003. Movilización, institucionalidad y legitimidad en Venezuela. En: Revista Venezolana de Economía y Ciencias Sociales, 9 (1), 211- 226.

LÓPEZ MAYA M.1996. Nuevas representaciones populares en Venezuela. En: Revista Nueva Sociedad, Num. 144. 138-151.

LUHMANN N.1973. La Ilustración Sociológica y otros ensayos. Buenos Aires: Editorial Sur.

LUHMANN N.1981. Cómo es posible el orden social. En: Morandé Pedro (trad.) Gesellschaftsstruktur und Semantik. Studien zur Wissensoziologie der modern Gesellshaft. Tomo 2. Frankfurt: Editorial Aufl.

LUHMANN N. 1990. Essays on Self-Reference. Columbia: Editorial Columbia University Press.

LUHMANN N. 1992. El futuro no puede empezar: estructuras temporales en la sociedad moderna. En: Ramos Ramón (ed.) Tiempo y Sociedad. DF: Editorial. Siglo XXI. 
LUHMANN N.1993. Teoría Política en el Estado de bienestar. Madrid: Alianza Editorial.

LUHMANN N.1995. Poder. DF: Editorial Anthropos.

LUHMANN N.1996. Confianza. DF: Editorial Anthropos.

LUHMANN N.1998. Sistemas Sociales: Lineamientos para una teoría general. DF: Editorial Anthropos, DF, México.

LUHMANN N. 1998. Teoría de los Sistemas Sociales (artículos I). DF: Editorial Universidad Iberoamericana.

LUHMANN N. 2000. Familiarity, Confidence, Trust: Problems and Alternatives. En: Gambetta, Diego (ed.). Trust: Making and Breaking Cooperative Relations. New York: Editorial Basil Blackwell.

LUHMANN N. 2007. La Sociedad de la Sociedad. DF: Editorial Herder.

MEDINA I. 2003. Sindicalismo Mexicano en Transición. DF: Editorial Libros Red.

MARIÑNZ F. 2000. Estado, Bienestar y Sociedad. La globalización y lo social. DF: Editorial Trillas.

MASCAREÑO A. 2009. Contingencia, necesidad e imposibilidad en la semántica de América Latina. En: Farías y Ossandon (Eds), Observando Sistemas II. DF: Ed. UIA.

MATURANA H. 2000. La ciencia y la vida cotidiana: la ontología de las explicaciones científicas. En: Watzlawick P. y Krieg P. (eds.). El ojo del observador. Barcelona: Editorial Gedisa.

MAINGON T. 2004. Política Social en Venezuela: 1999-2003. En: Revista Cuaderno Cendes, 21(55) 49-75.

MÉNDEZ ANA IRENE. 2006. Democracia y Discurso Político. Caracas: Ed. Monte Ávila.

MITZAL B.1996. Trust in Modern Societies. London: Editorial Polity Press.

NAFARRATE J. 2004. Luhmann: La política como sistema. DF: Editorial Fondo de Cultura Económica.

NAFARRATE J. 2007. Introducción a la Teoría de los Sistemas: lecciones. DF: Editorial Universidad Iberoamericana.

OFFE, C. 1999. How can we trust our fellowships? En: Warren, Mark (ed.) Trust and Democracy. Cambridge: Editorial Cambridge University Press.

PARSONS T.1974. El sistema de las sociedades modernas. DF: Editorial Trillas.

POULANTZAS N. (1979). Estado, poder y socialismo. DF: Editorial Siglo XXI.

ROMERO R. 2007. Los Consejos Comunales: más allá de la utopía. Maracaibo: Colección textos universitarios. 
SANJUÁN A. 2009. La esencia social de una revolución bolivariana en Venezuela: una mirada preliminar sobre sus fortalezas y debilidades. En: Arnson Cyntia (Ed.) La nueva Izquierda en América Latina. Washington: Editorial Woodrow Wilson International Center for Scholars.

VARELA F. 2002. Conocer. Las ciencias cognitivas: tendencias y perspectivas. Cartografía de las ideas actuales. Barcelona: Editorial Gedisa.

VANDERSTRAETEN R. 2000. Autopoiesis and Socialization: On Luhmann's reconceptualization of Communication and Socialization. En: Revista British Journal of Sociology, 51(3) 581-98.

VANDERSTRAETEN R. 2000. Luhmann on Socialization and Education. En: Revista Educational Theory, 50 (1) 1-23.

WEBER M. 1986. Ensayos de Sociología Contemporánea tomo I. DF: Editorial Artemisa.

ZOLO D. 1992. Democracy and Complexity. Pennsylvania: Editorial The Pennsylvania State University Press.

\section{Referencias electrónicas}

CEPAL. (2009). Estadísticas e indicadores [en línea]. Disponible en http://websie.eclac.cl/infest/ajax/cepalstat.asp?carpeta=estadisticas

CHÁVEZ H.(mayo 2003). Alo Presidente $N^{\circ} 150$ [en línea]. Disponible en http://alopresidente.gob.ve/component/option,com_docman/Itemid,0/task,cat_view/gi d,20/dir,DESC/order,date/limit,5/limitstart,160/

[Fecha de acceso: diciembre 27, 2009]

CHÁVEZ H. (marzo 2005). Alo Presidente $N^{\circ} 215$ [en línea]. Disponible en http://alopresidente.gob.ve/component/option,com_docman/Itemid,0/task,doc_downl oad/gid,54/

[Fecha de acceso: diciembre 27, 2009]

CHÁVEZ H.(junio 2005). Alo Presidente $N^{\circ} 225$ [en línea]. Disponible en: http://alopresidente.gob.ve/component/option,com_docman/Itemid,0/task,doc_downl oad/gid,64/

[Fecha de acceso: diciembre 27, 2009]

GOBIERNO BOLIVARIANO DE VENEZUELA (noviembre 2009). Qué es el Consejo Local de Planificación Pública [en línea]. Disponible en:

http://portal.gobiernoenlinea.ve/cartelera/ConsejoLocalPlanificacion.html [Fecha de acceso noviembre 10, 2009]

GOBIERNO BOLIVARIANO DE VENEZUELA (noviembre 2009). Proyecto Bolívar 2000 [en línea]. Disponible en:

http://portal.gobiernoenlinea.ve/cartelera/ConsejoLocalPlanificacion.html

[Fecha de acceso noviembre 10, 2009]

GOBIERNO BOLIVARIANO DE VENEZUELA (agosto 2007). Proyecto de reforma de la Constitución de la República Bolivariana de Venezuela [en línea].Disponible en http://www.hacer.org/pdf/RFC.pdf 
[Fecha de acceso: febrero 17, 2009]

GOBIERNO BOLIVARIANO DE VENEZUELA (marzo 2007). Cinco Motores Constituyente. Rumbo al Socialismo Bolivariano del siglo XXI [en línea]. Disponible en http://www.cicpc.gov.ve/files/mediateca/documentos/5motoresconstituyentes.pdf [Fecha de acceso: febrero 17, 2010 en:

MINISTERIO DEL PODER POPULAR PARA LA COMUNICACIÓN E INFORMACIÓN (febrero 2007). Agenda Alternativa Bolivariana [en línea]. Disponible en http://www.alopresidente.gob.ve/component/option,com_docman/Itemid,0/task,doc_d etails/gid,226/

[Fecha de acceso: diciembre 7, 2009]

PÉREZ A. (diciembre 2008). Análisis y reflexión del Plan Desarrollo Económico y Social 2007 - 2013 [en línea]. Disponible en

http://www.aporrea.org/actualidad/a51960.html

[Fecha de acceso: noviembre 18, 2009]

PARTIDO SOCIALISTA UNIDO DE VENEZUELA (mayo 2007). Blog de opinión y noticias relacionadas al Partido Unido Socialista de Venezuela [en línea]. Disponible en:

http://psuv.blogspot.com/

[Fecha de acceso: enero 15, 2009]

QUINTERO J. (junio 2005). Convenio Cuba-Venezuela: Respuesta inmediata a la salud del pueblo venezolano [en línea]. Disponible en http://www.minci.gob.ve/actualidad/2/5573/convenio_cubavenezuelarespuesta_inmediata.htm [Fecha de acceso diciembre 10, 2009]

REPÚBLICA BOLIVARIANA DE VENEZUELA (septiembre 2001).Plan de Desarrollo Económico y Social 2001-2007 [en línea]. Disponible en http://www.mpd.gob.ve/pdeysn/pdesn.pdf

[Fecha de acceso: noviembre 8, 2009]

\section{Notas}

${ }^{1}$ El 30 de octubre del 2000 se firma el convenio de cooperación integral entre la república de Cuba y Venezuela. Una parte de este convenio lo constituye un acuerdo energético, donde se estipula que Venezuela venderá a Cuba hasta 53.000 barriles de petróleo al año bajo un régimen preferencial de precios ( Elia 2006). En este mismo convenio, Cuba se compromete a ofrecer, en forma gratuita, los servicios médicos a los especialistas y técnicos en salud que serían trasladados a las zonas más desatendidas del país, así como colaborar en la formación médica de estudiantes venezolanos en Cuba y el tratamiento de pacientes venezolanos en instituciones de salud cubanas (Quintero 2005). Como sostiene Elia (2006), el Convenio permite que Cuba pueda vender a Venezuela bienes y servicios, entre los cuales se encuentran medicamentos, equipos y productos médicos.

${ }^{2}$ Como sostiene Ana María Sanjuán (2009), entre 2003 y 2008 se han puesto en marcha 25 misiones, sin embrago, las más importantes siguen siendo las que se encuentran en el cuadro cronológico.

${ }^{3}$ La ley de los Consejos Locales de Planificación Pública será reformada para el año 2006 (Gaceta Oficial número 38.591 del 2006. Como sostiene Romero (2007), se planetó la reforma de dicha ley para reforzar esa forma asociativa que ella misma creaba: los consejos comunales (Romero 2007). 